\title{
O Xokléng, o Kaingáng e sua filiação ao Proto-Jê: antecedentes para uma reflexão atual
}

Wilmar da Rocha D’Angelis ${ }^{1}$

\section{Resumo}

Este artigo visa apresentar uma recensão crítica dos cinco trabalhos pioneiros acerca da análise das relações entre Xokléng e Kaingáng, e entre essas línguas e a família Jê. Buscamos identificar, ao longo da análise, os aspectos que permanecem válidos nesses trabalhos e aqueles que mereceriam ser reanalisados, seja pela necessidade de proceder a uma reorganização dos dados, seja pela possibilidade atual de acrescentar novos dados em decorrência da maior quantidade de informações disponíveis tanto em relação ao Kaingáng quanto ao Xokléng.

Palavras-chave: Classificação linguística, Kaingáng, Xokléng, família Jê, Proto-Jê.

\begin{abstract}
This paper aims at a critical review of the five pioneering studies dealing with the genetic relations of Xokléng and Kaingáng, and of both languages and the Jê family. In our analysis we tried to identify the arguments for genetic relationship still valid, as well as those which should be reassessed, either by the reorganization of data or by the inclusion of new data now available for both Kaingáng and Xokléng.
\end{abstract}

Keywords: Language classification, Kaingáng, Xokléng, Jê family, Proto-Jê.

\section{Introdução}

O presente artigo resenha e discute os aspectos principais dos trabalhos pioneiros a respeito da filiação linguística do Xokléng e do Kaingáng à família Jê, produzidos entre as décadas de 1940 e 1970. Reunir, destacar e comentar os aspectos mais relevantes daqueles trabalhos é, por um lado, um indispensável gesto de reconhecimento acadêmico às pesquisas e trabalhos de precursores, e por outro, um exercício de leitura crítica que busca identificar, naqueles estudos, as conclusões parciais que permaneçam válidas para a continuidade da investigação acerca do Proto-Jê - e, em particular, do ProtoJê Meridional - ao mesmo tempo em que se busca identificar os aspectos ou

\footnotetext{
1 Professor do Departamento de Linguística do Instituto de Estudos da Linguagem (IEL), UNICAMP.
} 
conclusões parciais daqueles trabalhos que se mostram pouco sustentados ou, mesmo, contra-producentes para futuras pesquisas. ${ }^{2}$

A busca de interpretar a origem comum das línguas Kaingáng e Xokléng teve seu primeiro impulso por um trabalho do paranaense Rosário Farani Mansur Guérios, que publicou, em 1945, o trabalho O Xocrén é idioma Caingangue (Guérios 1945). Uma década e meia depois, Ursula Wiesemann produziu suas Notas sobre Proto-Kaingáng: um estudo de quatro dialetos (Wiesemann s.d. - seguramente de 1960 ou $1959^{3}$ ) e, mais uma década e meia depois, publicou seu estudo Os dialetos da língua Kaingáng e o Xokléng (Wiesemann 1978). O tema, nesses últimos trabalhos, já era o da reconstituição de um Proto-Kaingáng.

No campo da família Jê, e sem contar com dados do Kaingáng, Mattoso Câmara Jr. havia publicado, em 1959, o trabalho Alguns Radicais Jê, que é também de interesse quando nos ocupamos de reconstruir um Proto-Jê Meridional.

Na década de 1960, aproveitando sua estada na Universidade de Brasília (UnB), Irvine Davis produziu um importante estudo sobre Comparative Jê Phonology (Davis 1966), com base em dados de 5 línguas então em estudo por membros do SIL.

\section{2. "O Xocrén é idioma Caingangue" (Guérios 1945)}

Ao tempo em que Mansur Guérios ocupou-se da relação entre Xokléng e Kaingáng pairavam dúvidas, entre os pesquisadores, sobretudo antropólogos, acerca do parentesco dessas duas sociedades e suas culturas. Em seu preâmbulo, Guérios reproduz uma passagem de Francisco Schaden, em que ele afirma:

Quanto à classificação dos Aweikoma, conhecidos também como Xokren, Xokléng, Bugre e Botocudos de Santa Catarina (...) não se chegou ainda a um acordo entre os cientistas que os estudaram. Ao passo que uns os consideram Kaingáng, outros os apresentam como tribu isolada. Mediante exaustivo estudo e confronto dos idiomas, talvez se consiga dar uma resposta satisfatória à questão. (apud Guérios 1945:321).

\footnotetext{
${ }^{2} \mathrm{O}$ presente artigo corresponde à primeira (terça) parte do relatório de estágio pós-doc, intitulado "Pensar o Proto-Jê Meridional e revisitar o Proto-Jê, numa abordagem pragueana", produzido em 2007-2008, sob a supervisão de Aryon Rodrigues (LALI-UnB), com apoio do CNPq (Processo 155285/2006-8).

${ }^{3} \mathrm{Na}$ Introdução do trabalho a autora menciona que um resumo dele fora apresentado por ela na IV Reunião da Associação Brasileira de Antropologia, em Curitiba, em julho de 1959.
} 
Com base nos vocabulários que tinha disponíveis ${ }^{4}$, Guérios cotejou cerca de 70 itens lexicais, concluindo pelo indiscutível parentesco entre as duas línguas. Na verdade, tomando em conta a proposta de Čestmír Loukotka de uma família linguística Kaingáng, separada do grande grupo Jê , Guérios concluiu que o Xokléng é mesmo uma língua da família proposta.

Do estudo que fez, Guérios concluiu que o Xokléng seria, em relação ao Kaingáng, “....mais puro relativo aos fatos morfológicos; não o é em relação aos fonéticos. Estes são mais conservados em qualquer modalidade caingangue do Paraná que naquela." (Guérios 1945:328).

Guérios também sugere, com base nos argumentos a seguir enumerados, que os Xokléng experimentaram a

...substituição de uma língua por outra, denunciada pela concordância das 'leitwörter' como se viu acima (não só substantivos, adjetivos e verbos, porém principalmente os pronomes, os numerais e partículas)... a horda vencedora adotou o idioma dos vencidos (o caingangue), não por meio destes mesmos, os quais foram mortos, porém através das mulheres e crianças que foram preservados... (Guéiros 1945:329).

São três os argumentos nos quais Guérios baseia sua conclusão:

$1^{\circ}$ ) Há solução de continuidade glótica entre o caingangue do Paraná e o do Rio Grande do Sul, justamente em Santa Catarina. Grosso modo, há maior concordância fonética entre o Paraná e o extremo sul que entre Santa Catarina e os demais (...).

$\left.2^{\circ}\right) \mathrm{O} f$ do caingangue corresponde ao $z$ do xocrén. O fenômeno só é explicável por substituição (Lautersatz) e não por evolução (Lautwandel). E deste notável fato se deduz que a tribu aloglótica vencedora desconhecia o fonema $f$.

$3^{\circ}$ ) A língua que desapareceu (...) deverá ter deixado alguns elementos lexicais. Farão parte do substrato aqueles vocábulos (...) que eu não pude identificar? (Guérios 1945:329-330).

Assim concluía Guérios seu estudo, mas acrescentou-lhe um posfácio, em que dá notícias de uma carta de Curt Nimuendajú, em que este comenta aquelas conclusões. Escreveu Nimuendajú:

\footnotetext{
${ }^{4}$ Quatro vocabulários do Xokléng (ou três, um deles em duas versões) e quatro do Kaingáng (um dos quais, dele próprio, colhido em Palmas, PR). Guérios ainda aduziu a comparação de uma dezena de vocábulos Xokléng registrados por Jules Henry.

${ }^{5}$ Čestmír Loukotka, em trabalho de 1935, decidiu separar "o Kaingáng e línguas mais estreitamente afins" da família Jê, "e considerá-las como uma outra família, a família Kaingáng” (Rodrigues 2002:4).
} 
Eu não acho as divergências entre a língua Kaingáng e a dos Botocudos de Santa Catarina de uma natureza tal que se precisasse recorrer à hipótese de uma transferência da língua Kaingáng para um povo não-Kaingáng. (...) Quanto à substituição do $f$ Kaingáng por $z$ ( $s$ no vocabulário de Gensch) na língua dos Botocudos ela talvez se explica pela perfuração do lábio destes últimos. Mas também conheço por ex. dialetos de tupí puro (Kayabí, Wirafét, etc.) que substituem o $k w$ dos outros Tupí por $f$, e não creio que isto represente a forma original, e que os Tupí tivessem abolido o $f$ devido ao uso do tembetá (que, na verdade, aquelas tribus não usam). (Nimuendajú apud Guérios 1945:330).

\section{Notas sobre Proto-Kaingáng: um estudo de quatro dialetos}

Sob o título acima (na versão portuguesa de Miriam Lemle ${ }^{6}$ ), Ursula Wiesemann produz uma reconstrução do Proto-Kaingáng e apresenta a tese de que o Kaingáng comporta quatro dialetos (cada um apresentando "variações menores"): Dialeto Paraná (entre o Rio Iguaçu e o Paranapanema); Dialeto Sul (ao Sul do Rio Iguaçu); Dialeto de São Paulo (ao norte do Paranapanema); e o Xokléng. ${ }^{7}$

O trabalho teve por base uma pesquisa de campo realizada em oito áreas Kaingáng nos quatro estados do Sul (de São Paulo ao Rio Grande do Sul), de fevereiro a março de 1958, "sob os auspícios do Museu Nacional" (Wiesemann s.d.:1). Em cada área, segundo a autora, foi feito o registro de dados no "Questionário Padrão para a Pesquisa nas Línguas Indígenas Brasileiras" (Museu Nacional 1957).

Registre-se, como valiosa, a seguinte observação de Wiesemann a respeito dos fonemas do Xokléng: "Tem $/ r /$, que difere dos outros dialetos pelo fato de apresentar um alofone $/ l /$, que ocorre em início de palavra e entre vogais não-nasalizadas." (Wesemann 1978:3).

A observação confirma, em parte, o que dissera Jules Henry (1948:194), de uma perspectiva inversa: "Between vowels 1 is often replaced by a single flapped $r "$

São importantes esses registros, uma vez que para o Xokléng atual isso não é mais observado. Bublitz, em análise fonológica dessa língua produzida

\footnotetext{
${ }^{6}$ Original: Notes on Proto-Kaingáng: a study of four dialects (mimeo).

${ }^{7} \mathrm{Na}$ verdade a distinção do Kaingáng em três dialetos (mantendo o Xokléng como língua aparentada, mas à parte) fora uma proposta de Nimuendajú, que distinguira um Dialeto do Norte (SP e Laranjinha), um Dialeto Central (entre o Iguaçu e o Paranapanema) e um Dialeto do Sul (in Nimuendajú e Guérios 1948).
} 
na década de 1990, reconhece um fonema / $l /$ ('flap' lateral) que tem [ $r$ ] como um alofone que ocorre "em variação livre com $[l]$ " apenas "depois de consoante oclusiva surda" (Bublitz 1994:26).

Curiosamente, Wiesemann, no mesmo trabalho acima citado, diz que "os dialetos de Paraná, do Sul e de São Paulo têm todos $|f|$ e $/ r /$ com aproximadamente os mesmos alofones em cada dialeto" (Wesemann 1978:2). Ora, isso é bastante diferente do que observamos, pessoalmente, no dialeto de São Paulo em 1999 e 2000 (portanto, 40 anos depois de Wiesemann). Ali, diferente do que acontece nos dialetos Kaingáng do Paraná, de Santa Catarina e do Rio Grande do Sul, encontramos exatamente uma distribuição complementar entre $[l]$ e $[f]$, com o primeiro ocorrendo no início de palavras, e o segundo em posição medial (intervocálica e como segunda consoante em sílabas $\mathrm{CCV}$ e CCVC) ${ }^{8}$. Em outras palavras, tomando em conta as observações de Henry, e as observações de Wiesemann com respeito ao Xokléng (mas não com respeito ao Kaingáng paulista), em confronto com minhas próprias observações a respeito do Kaingáng de São Paulo, chamo a atenção para esse traço compartilhado entre a fonologia do dialeto paulista e a fonologia do Xokléng com relação ao fonema da classe das líquidas. Informações como essa serão relevantes para a construção de hipóteses a respeito das relações internas entre línguas e dialetos no âmbito da sub-família Jê Meridional.

Segundo as conclusões de Wiesemann, de sua análise inicial resultou que ...todos os dialetos tinham os seguintes fonemas consonantais, com aproximadamente os mesmos alofones ou submembros em cada dialeto: $|b /| d,|| g,|| h,|| k,|| m,|| n,|| g,||, p /,|t|,|v|,|y|$. De acordo porém com a análise fonêmica atualmente estabelecida para o dialeto do Paraná falado em Rio das Cobras, $/ b /, \mid d /, / g /$ não constituem fonemas. (Wiesemann 1978:2).

Quanto às vogais, "todos os dialetos foram analisados como tendo os seguintes fonemas vocálicos: $|a|,|\varepsilon|,|e|,|i|,|i|,|o /,| \jmath /,|u| "$, na série oral, além de $/ \partial /$, que "devido à raridade de sua ocorrência" a autora hesitou em considerar fonema, mas, posteriormente, à luz de análise mais demorada do dialeto de Rio das Cobras, confirmou-lhe aquele estatuto. Por outro lado, ...nos dados do 'survey' foi registrada uma contraparte nasalizada de todas as vogais, exceto $\dot{i}$. $\mathrm{O}$ ẽ foi registrado apenas no dialeto Xokreng, $\tilde{o}$ e $\tilde{u}$ não contrastam no dialeto do Paraná

\footnotetext{
${ }^{8}$ Cf. D’Angelis 2005a.
} 
de Rio das Cobras, sendo manifestações do mesmo fonema /õ/. $\tilde{a}$ e $\tilde{\jmath}$, do mesmo modo, não contrastam nesse dialeto mas são manifestações do fonema /ã/. (Wiesemann 1978:3).

Apesar dessas conclusões aparentemente bem estabelecidas, Wiesemann informa, adiante, que "a nasalização não foi registrada de maneira consistente", de modo que, para a reconstrução do quadro vocálico, segundo ela, "reconstituímos a qualidade das vogais, sem referência a sua modificação pela nasalização" (Wiesemann 1978:4). É evidente que o resultado de uma tal reconstituição não poderia ser minimamente confiável.

A partir, pois, do cotejamento de cognatos, Wiesemann (s.d.:4-10) reconstrói os seguintes protofonemas consonantais (ilustramos, aqui, com o primeiro exemplo de Wiesemann em cada caso $)^{9}$ :

\begin{tabular}{|c|c|c|c|c|c|c|}
\hline PK & \multicolumn{2}{|c|}{ correspondências } & PR & Sul & SP & Xokléng \\
\hline$* b$ & $b: b: b: b$ & ex.: & kibm & kibm & kibm & kibm \\
\hline$* \mathrm{~d}$ & $\mathrm{~d}: \mathrm{d}: \mathrm{d}: \mathrm{d}$ & ex.: & -mbcdn & mbedn & medn & mbedn \\
\hline$*_{n d} d^{10}$ & nd:nd:nd:j & ex: & ndyidn & ndidn & nyidn & -juydn \\
\hline$*_{\mathrm{f}}$ & f:f:v:ð ${ }^{11}$ & ex.: & -fərə & firi & firi & ðiri \\
\hline$* g$ & $g: g: g: g$ & ex.: & gga & yga & jga & 1gอ \\
\hline$* \mathrm{~h}$ & h:h:h:h & ex.: & hẽri- & hẽri & 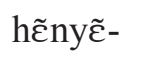 & hãri- \\
\hline$*_{\mathrm{k}}$ & $\mathrm{k}: \mathrm{k}: \mathrm{k}: \mathrm{k}$ & ex.: & kãntĩn & kẽntĩ̄ & kãntĩy & katĩn \\
\hline & & & & ou kõntĩn & & \\
\hline$* \mathrm{~m}$ & m:m:m:m & ex.: & -tãmẽ & tãmẽ & tãmẽ & tomã \\
\hline$*_{\mathrm{n}}$ & n:n:n:n & ex.: & nĩ̄rẽ̄ & nĩ̄grẽ̄ & nĩ̄grẹ̃ & nĩrạ̃ \\
\hline$* \eta$ & 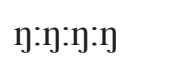 & ex.: & tãy & tãy & tẽ $\eta$ & $\operatorname{tag} \eta$ \\
\hline & & & & ou tẽ̄ & & \\
\hline & & & & ou tõy & & \\
\hline$* \mathrm{p}$ & p:p:p:p & ex.: & pə̃n & pə̃n & pə̃n & põn \\
\hline
\end{tabular}

\footnotetext{
${ }^{9} \mathrm{~A}$ ordem alfabética é do original, de Wiesemann.

${ }^{10}$ Sobre esse possível protofonema, Wiesemann declara: "Interpretou-se $n d$ como uma sequência de $n$ mais $d$ em lugar de um $d$ pré-nasalizado, ficando reconstruído como uma protossequência *nd. É ela atualmente interpretada como uma unidade subfonêmica no dialeto do Paraná, e talvez venha a ser assim considerada na protolíngua" (s.d.:5)

${ }^{11}$ Wiesemann emprega, como símbolo para o som correspondente em Xokléng, um $d$ cortado (seguindo a notação fonética adotada por K. Pike). Aqui adotamos o símbolo empregado em Henry (1948).
} 


\begin{tabular}{|c|c|c|c|c|c|c|}
\hline$*_{r}$ & r:r:r:r & ex.: & -yakrĩ & yakrĩ & yakrĩ & nyכ̃krẽ \\
\hline$*_{\mathrm{t}}$ & $t: t: t: t$ & ex.: & $\mathrm{ti}$ & $\mathrm{ti}$ & $\mathrm{ti}$ & tia ou ti- \\
\hline *č & š: ̌s::̌̌čč & ex.: & kuša & kuša & kuča & kučo \\
\hline$*_{\mathrm{V}}$ & $\mathrm{v}: \mathrm{v}: \mathrm{v}: \mathrm{V}$ & ex.: & kiveydn & kivegn & kiveydn & kivey \\
\hline$*_{\mathrm{y}}$ & y:y:y:y & ex.: & yẽ̃ & 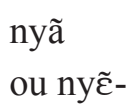 & $-\mathrm{y} \tilde{\varepsilon}$ & -yãn- \\
\hline
\end{tabular}

Wiesemann conclui por um "sistema fonêmico" da Protolíngua "semelhante aos sistemas dos dialetos que daí se desenvolveram" (s.d:16), assim configurado:

$\begin{array}{ccc}\mathrm{p} & \mathrm{t} & \mathrm{k} \\ \mathrm{b} & \mathrm{d} & \mathrm{g} \\ \mathrm{m} & \mathrm{n} & \mathrm{y} \\ \mathbf{f} & \check{\mathbf{c}} & \mathbf{h} \\ \mathbf{v} & \mathbf{y} & \mathbf{r}\end{array}$

Para as vogais, eis a reconstrução formulada por Wiesemann (s.d.:10-16):

\begin{tabular}{|c|c|c|c|c|c|}
\hline correspondências & & PR & Sul & SP & Xokléng \\
\hline $\mathrm{a}: \varepsilon / \mathrm{a} / \supset: \varepsilon: \mathrm{a}^{12}$ & ex.: & tãy & 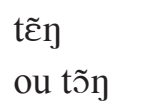 & $\mathrm{t} \tilde{\varepsilon} \eta$ & tagn \\
\hline a:a:a:っ & ex.: & kaytkã & 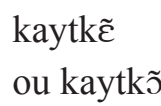 & kaytk $\tilde{\varepsilon}$ & kəytka \\
\hline$\varepsilon: \varepsilon: \varepsilon: a$ & ex.: & 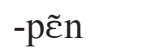 & pẽn & pẽn & pãn \\
\hline$\varepsilon: \varepsilon: \varepsilon: \varepsilon^{13}$ & ex.: & 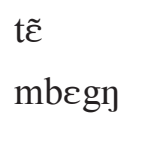 & 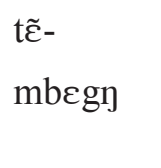 & $\begin{array}{l}\text { t } \tilde{\varepsilon}- \\
m \varepsilon k\end{array}$ & 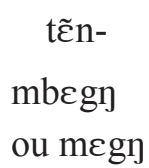 \\
\hline e:e:e:e & ex.: & $\begin{array}{l}\text { kupe } \\
\text { ou kupe }\end{array}$ & $\begin{array}{l}\text { kupe- } \\
\text { ou kupe }\end{array}$ & kupe- & kupe- \\
\hline
\end{tabular}

\footnotetext{
${ }^{12}$ A autora esclarece que "as linhas oblíquas mostram, nesta fórmula, a flutuação entre $\varepsilon$, $a$, e $\supset$ no dialeto do Sul. Somente as vogais nasalizadas flutuam dessa maneira. $\tilde{\varepsilon}$ e $\tilde{a}$ são fonemas plenos (...), enquanto que a flutuação entre $\tilde{a}$ e $\tilde{s}$ é subfonêmica no dialeto do Paraná" (s.d.:10)

${ }^{13}$ Aqui se dão dois exemplos para ilustrar a afirmação (da própria Wiesemann) de que ela mistura vogais orais e nasais. Observe-se, por ex., que em Kaingáng $/ k \tilde{\varepsilon} \tilde{\varepsilon} /$ e $/ k r \varepsilon /$ (e em Xokléng, $/ k l \tilde{\varepsilon} / \mathrm{e} / k l \varepsilon /$ ) constituem um par mínimo.
} 


\begin{tabular}{|c|c|c|c|c|c|c|}
\hline$*_{\mathrm{i}}$ & $\mathrm{i}: \mathrm{i}: \mathrm{i}: \mathrm{i}^{14}$ & ex.: & $\begin{array}{l}\text {-nĩ̄ka } \\
\text { piri }\end{array}$ & $\begin{array}{l}\text { nĩjka } \\
\text { piri }\end{array}$ & $\begin{array}{l}\text { nĩjka } \\
\text { piri }\end{array}$ & $\begin{array}{l}\text { nĩjko } \\
\text { piri }\end{array}$ \\
\hline$*_{1}$ & i:i:i:e & ex.: & -nĩ & $-n \tilde{1}$ & $-n \tilde{}$ & -nẽ \\
\hline$*_{\dot{i}}$ & i:ìi:i & ex.: & kuti & kuti & kuti & kutign \\
\hline \multicolumn{7}{|c|}{$*_{\partial} 15$} \\
\hline$*_{\mathrm{O}}$ & o:o:o:o & ex.: & ko & ko & ko & ko \\
\hline$*_{0}$ & ๑:১:১:u & ex.: & -yəgฤ & -yog- & -yวg- & nyugn \\
\hline$*_{U}$ & o:o:o:u & ex.: & -nõn & nõn & nõn & nũnã ${ }^{16}$ \\
\hline$*_{\mathrm{u}}$ & u:u:u:u & ex.: & kupri & kupri & kupri & kupri \\
\hline
\end{tabular}

A reconstituição acima resulta no seguinte quadro de protofonemas vocálicos (s.d.:16):

$\begin{array}{ccc}\mathrm{i} & \mathrm{i} & \mathrm{u} \\ \mathrm{l} & & \mathrm{U} \\ \mathrm{e} & \partial & \mathrm{o} \\ \varepsilon & & 0 \\ æ & \mathrm{a} & \mathrm{D}\end{array}$

No entanto, observou a autora, que tal sistema vocálico

...apresenta $* l, * U, * \mathfrak{x} e^{*} p$ que não são encontrados em nenhum desses dialetos. Uma reconstrução que levasse em conta as qualidades oralnasal das vogais chegaria provavelmente ao seguinte protossistema. (Wiesemann s.d:16)

Vogais orais

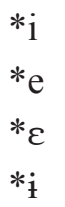

Vogais nasais:

$$
\begin{aligned}
& *_{\tilde{1}} \\
& * \tilde{e} \\
& * \tilde{\varepsilon}
\end{aligned}
$$

\footnotetext{
${ }^{14}$ Ver nota anterior.

${ }^{15} \mathrm{Na}$ sequência da apresentação de * $i$, a autora aduz: " $i$ e $ə$ foram encontrados contrastando no dialeto do Paraná (...), constituindo, portanto, fonemas separados". Porém a dificuldade sentida pela autora em ouvir essa distinção, a não ser em listas contrastivas, sugere que a audição desse contraste em outros dialetos indicaria imprecisão de registro. Especificamente, “...é admissível a possibilidade de que, em dados corrigidos, algumas das irregularidades, se não todas, (...) pertençam na verdade, a uma série de correspondências $ə$ : ə : ə : ə que seriam reconstruídas como um proto-fonema *ə."

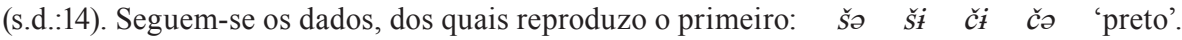

${ }^{16}$ Todos os exemplos, no caso do protofonema * $U$ são com vogais nasais.
} 


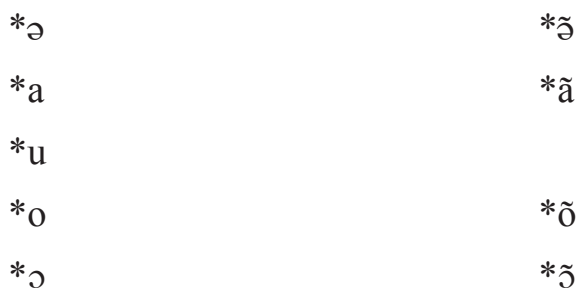

Esse conjunto representa um quadro simplificado em relação ao anterior e, nas palavras da autora, "este sistema fonêmico do proto-kaingáng é muito semelhante ao das línguas da família Jê, o que é de se esperar, se o Kaingáng for realmente relacionado com o Jê, conforme foi postulado" (Wiesemann s.d.:16).

Wiesemann faz, ainda, uma avaliação estatística com base nas proposições de Swadesh acerca do grau de parentesco de línguas a partir do percentual de itens lexicais cognatos. Por aquela avaliação,

...somente os dialetos do Paraná e do Sul seriam dialetos da mesma língua; todos os outros dialetos de Kaingáng seriam chamados línguas da mesma família, tendo entre si o mesmo grau de parentesco que há entre o alemão e o inglês, por exemplo. (Wiesemann s.d.:17).

A autora discorda, considerando que “...a classificação de Swadesh exagera a distância entre os dialetos de Kaingáng" já que ela, como falante tanto de alemão quanto de inglês, avalia que "as diferenças entre estes dialetos de Kaingáng não são nem de longe tão grandes como as diferenças entre o inglês e o alemão." (Wiesemann s.d.:17).

De todo modo, Wiesemann interpreta os resultados percentuais como

...um quadro verossímel dos dialetos em contato parcial durante a diferenciação. Parece que a ruptura entre os extremos da área - São Paulo, Xokreng e Sul - foi anterior e mais completa, enquanto que o contato de Paraná com cada um dos outros continua. A cisão mais recente se deu entre os dialetos de Paraná e do Sul. (Wiesemann s.d.:17).

\section{Os dialetos da língua Kaingáng e o Xokléng}

Neste trabalho, publicado quase 20 anos depois do resenhado acima, Wiesemann apresenta suas conclusões a respeito da existência de cinco dialetos na língua Kaingáng, distinguindo-a, também, do Xokléng. 
Entre um trabalho e outro, ela destaca ter concluído seu estudo do dialeto do Paraná (com base em Rio das Cobras) e realizado “...extensos estudos da fala dos habitantes de todos os P.I. onde moram índios Kaingáng.”, além de “...um estudo mais aprofundado da língua Xokléng.” (Wiesemann 1978:199). O que Wiesemann não esclarece é a forma como se deram aqueles "extensos estudos", ou os meios que os proporcionaram. De fato, na década de 1970 o Summer Institute of Linguistics - ao qual Wiesemann estava integrada e que missionava os Kaingáng em Rio das Cobras, PR - e a IECLB (Igreja Evangélica de Confissão Luterana no Brasil ${ }^{17}$ ), que mantinha uma missão entre os Kaingáng em Guarita (RS), firmaram convênio com a FUNAI e, com recursos do exterior ${ }^{18}$, instalaram e mantiveram uma escola de formação de "monitores" (professores) indígenas e técnicos agrícolas índios. A escola, denominada Centro de Treinamento Profissional Clara Camarão (CTPCC) funcionava na área indígena Guarita, no município de Tenente Portela (RS). Para lá foram encaminhados jovens Kaingáng de ambos os sexos, provenientes de praticamente todas as áreas indígenas do Sul do país. Os cursos não tinham propriamente um equivalente no currículo escolar brasileiro (a maioria dos jovens levados a cursá-lo havia feito as 4 séries iniciais nas escolas de suas áreas), mas duravam três anos, formando professores (que o Summer sempre denominou Monitores) e "técnicos agrícolas". Deslocados para uma outra área indígena, mas em um regime de internato dirigido e controlado por não-índios evangélicos proselitistas (vários deles estrangeiros, e os demais, quase todos descendentes de imigrantes alemães), aqueles jovens Kaingáng viveram uma forte experiência de desenraizamento na própria terra. ${ }^{19}$ Segundo depoimento de vários que conhecemos pessoalmente, aos finais de semana as moças eram levadas ao "salão de beleza", na cidade, caracterizando o projeto em questão de "religioso-civilizatório". Nesse contexto é que as jovens eram, com frequência, colocadas "de castigo", o que significava hospedar-se e realizar trabalhos domésticos na casa de "Dona Úrsula". Ali, durante dias ou semanas, deviam também prestar o

\footnotetext{
${ }^{17}$ A IECLB é formada basicamente sobre comunidades de descendentes de alemães no Sul do Brasil (mas também no Espírito Santo, Mato Grosso, Rondônia e onde mais se transmigraram colonos do Sul) e tem sede em Porto Alegre. Sua ação junto aos índios é dirigida pelo COMIN - Conselho de Missão entre Índios.

${ }^{18}$ A maior parte dos fundos, ao que parece, proveio da organização alemã Brot für die Welt (Pão para o Mundo).

${ }^{19} \mathrm{Na}$ sua grande maioria, eles tornaram-se evangélicos (de diferentes denominações), e alguns até mesmo pastores. Das moças, várias buscaram casamentos com não-índios, incluindo Chefes de Posto ou Técnicos da FUNAI.
} 
serviço de informante linguístico, com o que, a missionária pode reunir o material necessário aos seus estudos comparativos. ${ }^{20}$

Wiesemann distingue, então, didaticamente, cinco dialetos Kaingáng (Wiesemann 1978:199-200 - ver Anexo 9 deste trabalho):

Dialeto de São Paulo - "entre Tietê e Paranapanema", ${ }^{21}$ que seria falado nas áreas de Vanuíre, Icatu e Araribá (todas em São Paulo). ${ }^{22}$

Dialeto do Paraná - "entre Paranapanema e Iguaçu”, que seria falado nas áreas de Apucarana, Barão de Antonina, Queimadas, Ivaí, Faxinal, Rio das Cobras e Guarapuava (todas no Paraná).

Dialeto Central - "entre Iguaçu e Uruguai”, que seria falado nas áreas de Mangueirinha, Palmas (PR) e Xapecó (SC).

Dialeto Sudoeste - "ao sul do Uruguai, oeste do Passo Fundo", que seria falado nas áreas de Nonoai, Guarita e Inhacorá (RS).

Dialeto Sudeste - "ao sul do Uruguai, leste do Passo Fundo", que seria falado nas áreas de Votouro, Ligeiro, Carreteiro e Cacique Doble (RS).

Wiesemann não menciona: (i) no Paraná, as áreas de São Jerônimo (que é um desdobramento de Barão de Antonina, ou vice-versa); Mococa, que via como uma simples extensão de Queimadas; e Boa Vista, então dada como extinta, cuja população estava, na maior parte em Guarapuava. (ii) em Santa Catarina, as áreas de Toldo Chimbangue e Toldo Pinhal, então consideradas extintas (na verdade, praticamente desconhecidas) e Kondá (criada no final do século para abrigar grupos migrantes do RS). (iii) no Rio Grande do Sul, as áreas de Iraí, por que à época era apenas um 'acampamento'; Ventarra, Serrinha e Caseros, que eram, então, dadas como extintas, e foram retomadas pelos índios entre as décadas de 1980 e 1990; e Rio da Várzea, que era considerada apenas uma aldeia de Nonoai.

\footnotetext{
${ }^{20}$ Temos depoimentos gravados em vídeo de indígenas que estudaram, quando jovens, no CTPCC e, igualmente, tivemos acesso a depoimentos escritos, apontando no mesmo sentido. Um depoimento escrito, que tivemos ocasião de ler no Rio Grande do Sul, fora produzido por uma ex-interna do CTPCC com vistas a uma publicação acadêmica, mas a publicação não aconteceu por forte pressão da própria Wiesemann sobre a autora do relato.

${ }^{21}$ No original, nesta e na referência a seguir, aparece Paranapena, por engano.

${ }_{22}$ As áreas de Icatu e Vanuíre são, de fato, terras (ínfimas) reservadas aos Kaingáng paulistas. Araribá era a denominação de então para uma área reservada aos Guaraní. Atualmente, na primeira há também população Terena (oriunda do MS) e na segunda, população Krenak (oriunda de MG), e nas duas os Kaingáng são hoje minoria. Em Araribá há também população Terena (que levou à divisão das terras, no final da década de 1980) e sempre houve, mais ou menos de passagem, uma ou outra família Kaingáng. Para localização e mais informações sobre cada área indígena Kaingáng, veja-se www.portalKaingáng.org.
} 
Quanto à classificação dos cinco dialetos, embora didática, não é segura ou razoável em muitos aspectos. Não vamos nos aprofundar nisso, mas basta dizer, por exemplo, que no Paraná, a população Kaingáng não é tão homogênea quanto pareceria; em Santa Catarina, Xapecó sempre foi ponto de passagem e contato inter-grupos, do Paraná com Rio Grande do Sul, pelo menos desde meados do século XIX; no Rio Grande do Sul, Nonoai tem mais afinidade histórica e política (e maior proximidade geográfica) com Votouro do que com Guarita e Inhacorá; e Cacique Doble, Ligeiro e Carreteiro têm muitas relações históricas comuns, que os distinguem de Votouro, com eles agrupados no "Dialeto Sudeste".

Wiesemann apresenta os seguintes sistemas fonológicos consonantais, para os dialetos do Kaingáng e para o Xokléng:

\begin{tabular}{|c|c|c|c|c|c|c|c|c|c|c|c|c|c|}
\hline \multicolumn{5}{|c|}{ DIALETOS PR, C, SO, SE } & \multicolumn{5}{|c|}{ DIALETO SP ${ }^{23}$} & \multicolumn{4}{|c|}{ XOKLÉNG ${ }^{24}$} \\
\hline p & $\mathrm{t}$ & & $\mathrm{k}$ & $?$ & $\mathrm{p}$ & $\mathrm{t}$ & $\check{c}$ & $\mathrm{k}$ & $?$ & $\mathrm{p}$ & $\mathrm{t}$ & $\check{c}$ & $\mathrm{k}$ \\
\hline $\mathrm{m}$ & $\mathrm{n}$ & $\tilde{\mathrm{n}}$ & $\eta$ & & $\mathrm{m}$ & $\mathrm{n}$ & $\tilde{\mathrm{n}}$ & $\eta$ & & $\mathrm{m}$ & $\mathrm{n}$ & $\tilde{\mathrm{n}}$ & $\eta$ \\
\hline $\mathrm{f}$ & & $\breve{\mathrm{s}}$ & & $\mathrm{h}$ & & & & & & $\mathrm{d}$ & $\mathrm{d}$ & & \\
\hline $\mathrm{V}$ & $\mathrm{r}$ & $\mathrm{j}$ & & & $\mathrm{v}$ & $\mathrm{r}$ & j & & $\mathrm{h}$ & $\mathrm{v}$ & 1 & $\mathrm{j}$ & \\
\hline
\end{tabular}

A autora procede, então, a novo esforço de reconstrução do ProtoKaingáng (PK) “...através dos reflexos em K e X, levando em consideração os reflexos de Proto-Jê (PJ).” (Wiesemann 1978:200). Disso resultou o seguinte sistema consonantal, proposto para o Proto-Kaingáng:

$\begin{array}{lllll}\mathrm{p} & \mathrm{t} & \check{\mathrm{c}} & \mathrm{k} & (\mathrm{l}) \\ \mathrm{m} & \mathrm{n} & \tilde{\mathrm{n}} & \mathrm{g} & \\ \mathrm{v} & \mathrm{r} & \mathrm{j} & & \mathrm{h}\end{array}$

Observa-se sua quase identidade com o sistema proposto para o Kaingáng de São Paulo, acima.

Para as vogais, Wiesemann (1978:203) apresenta os seguintes conjuntos de fonemas ${ }^{25}$ :

\footnotetext{
${ }^{23}$ No Dialeto SP, “.../c/ se pronuncia $[t \check{s}]$ ou $[\check{s}], / r /$ se pronuncia $[r]$ ou $[l] . ”$ (Wiesemann 1978:200).

${ }^{24}$ Em Xokléng, ".../l/ flutua entgre $[l]$ e $[r]$ em grupos de $C$; a fonemicidade de $/ R /$ não foi bem estabelecida." (Wiesemann 1978:200).

${ }^{25}$ Transpusemos, nas tabelas abaixo, para os símbolos do IPA, os quadros que Wiesemann apresenta em forma ortográfica. Quanto a $\tilde{e}$ e $\tilde{o}$, por falta de indicação quanto à abertura da vogal, mantivemos com esses símbolos.
} 


\begin{tabular}{|c|c|c|c|c|c|c|c|c|c|}
\hline \multicolumn{3}{|c|}{ Vogais orais } & \multicolumn{2}{c|}{ Vogais nasais } & \multicolumn{3}{c|}{ Vogais nasais } & \multicolumn{2}{c|}{ Vogais nasais } \\
KGG e XKL & \multicolumn{2}{c|}{ KGG SP, C, SO } & \multicolumn{3}{c|}{ KGG PR, SE } & \multicolumn{2}{c|}{ XOKLÉNG } \\
\hline $\mathrm{i}$ & $\dot{\mathrm{i}}$ & $\mathrm{u}$ & $\tilde{\mathrm{i}}$ & $\tilde{\mathrm{u}}$ & $\tilde{\mathrm{i}}$ & $\tilde{\mathrm{t}}$ & $\tilde{\mathrm{u}}$ & $\tilde{\mathrm{e}}$ & $\tilde{\mathrm{u}}$ \\
\hline $\mathrm{e}$ & $\mathrm{\partial}$ & $\mathrm{o}$ & $\tilde{\mathrm{e}}$ & $\tilde{\mathrm{i}}$ & $\tilde{\mathrm{e}}$ & $\tilde{\mathrm{a}}$ & & $\tilde{\mathrm{a}}$ & $\tilde{\mathrm{o}}$ \\
\hline $\mathrm{e}$ & $\mathrm{a}$ & 0 & & & & & & & \\
\hline
\end{tabular}

A autora adverte que "embora o sistema das vogais orais seja igual em todos os dialetos do Kaingáng e em Xokléng, os reflexos são diferentes em várias partes da estrutura" (Wiesemann 1978:203). E reconstitui, para o Proto-Kaingáng, o seguinte sistema vocálico (Wiesemann 1978:204) ${ }^{26}$ :

\section{VOGAIS ORAIS}

$\begin{array}{lll}\mathrm{i} & \mathrm{i} & \mathrm{u} \\ \mathrm{e} & \partial & \mathrm{o} \\ \varepsilon & \Lambda & 0\end{array}$

a

\section{VOGAIS NASAIS}

$\begin{array}{ll}\tilde{\mathrm{i}} & \tilde{\mathrm{u}} \\ \tilde{\mathrm{e}} & \tilde{a}\end{array}$

$\mathrm{O}$ artigo traz, ainda, algumas observações morfofonêmicas e morfológicas. Entre as primeiras, destaco o resultado de sequências heterossilábicas $n+t$, que nos dialetos do Paraná e do Sul produz [ $/]$ (ex: in $\left.+t \tilde{u}=\left[i^{\prime} \tilde{u}\right]\right)$, enquanto no Xokléng produz o correspondente $\left.[t]\right]$ (ex.: $\tilde{e} n+$ tũ $=[\tilde{e} t f \tilde{u}]$ ), e no dialeto de São Paulo resulta ou em [ $\left.\tilde{l}^{\prime} t \tilde{u}\right]$ ou em $[\tilde{\imath} t f \tilde{u}]$ (cf. Wiesemann 1978:207).

Entre as morfológicas, destaque-se o que Wiesemann assim descreveu:

Em PR muitos substantivos e descritivos têm duas formas, como por exemplo:

ka $\sim$ kã 'árvore' (su) kusa $\sim$ kusã 'frio' (d)

Estas variantes perderam-se em todos os outros dialetos e em X, mas encontram-se em certas expressões fixas, indicando que são formas antigas e não uma inovação de PR:

$\begin{array}{lllll}\text { SP } & \text { kuča } & \text { 'frio' } & \text { kučẽ kamẽ } & \text { 'muito frio' } \\ \text { PR } & \text { kuša } & \text { 'frio' } & \text { kušã pẽ } & \text { 'muito frio' } \\ \text { C, SO } & \text { kuša } & \text { 'frio' } & \text { kušẽ kamẽ } & \text { 'muito frio' } \\ \text { SE } & \text { kuša } & \text { 'frio' } & \text { kušã kamẽ } & \text { 'muito frio' } \\ \text { X } & \text { kučó } & \text { 'frio' } & \text { kuča kómã } & \text { 'muito frio' }\end{array}$

(Wiesemann 1978:207-208)

\footnotetext{
${ }^{26}$ Ver nota anterior.
} 
Essa observação, de fato, pode se mostrar relevante para as conclusões a que queremos chegar a respeito das relações genéticas dentro do subgrupo de línguas Jê Meridionais.

A autora também aponta o fato comum ao Xokléng e ao Kaingáng de (à exceção do dialeto de São Paulo) existirem verbos com uma única forma (ex.: X. e K. nen ), verbos com duas formas (ex.: X. ko $\sim$ ku, K. ko kó), verbos com três formas (ex.: X. e K. vê vé vég ), verbos com quatro formas (ex.: X. $\eta e \sim \eta \mathcal{E} \sim \eta \varepsilon \bar{\eta} \eta \eta \varepsilon \eta$; K. $f a \sim f \tilde{a} \sim f \tilde{a} n \sim f \tilde{a} \eta$ ) (cf. Wiesemann 1978:208.).

Uma característica sintática do Kaingáng é a marcação do Sujeito. Wiesemann avaliou as diferenças dialetais, com relação a isso, concluindo:

Em PR e SP o sujeito frequentemente, mas nem sempre, é marcado por um indicador de sujeito. Em PR o indicador mais frequente é tón; em SP são $v \tilde{y}, n \tilde{y}, n e$. Nos outros dialetos o sujeito sempre é marcado. Em SO tó $\sim$ tón flutua com tỹy ta. tỹ em PR sempre indica instrumental (que nas orações sem sujeito indica

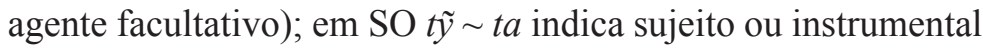
- agente em todo caso. (Wiesemann 1978:211).

O artigo encerra-se com um quadro síntese, do qual apresento, abaixo, alguns pontos mais relevantes ${ }^{27}$ :

\begin{tabular}{|c|c|c|c|c|c|}
\hline SP & PR & $\mathrm{C}$ & $\mathrm{SO}$ & SE & $X$ \\
\hline 1 & $\check{\mathrm{s}}$ & $\check{\mathrm{S}}$ & $\check{\mathrm{s}}$ & $\check{\mathrm{S}}$ & $\check{c}$ \\
\hline 3 & $\mathrm{f} / \mathrm{v}$ & $\mathrm{f} / \mathrm{v}$ & $\mathrm{f} / \mathrm{v}$ & $\mathrm{f} / \mathrm{v}$ & ठ/v \\
\hline $\mathrm{r} / \mathrm{l}$ & $\mathrm{r}$ & $\mathrm{r}$ & $r$ & $\mathrm{r}$ & $1 / \mathrm{r}$ \\
\hline 5 & $\mathrm{a}$ & $\mathrm{a}$ & $\mathrm{a}$ & $\mathrm{a}$ & õ \\
\hline 6 & 0 & 0 & 0 & 0 & $\mathrm{u}$ \\
\hline$\tilde{\mathrm{e}}$ & $\tilde{\mathrm{a}} / \tilde{\mathrm{e}}$ & $\tilde{\mathrm{e}}$ & $\tilde{\mathrm{e}}$ & $\tilde{\mathrm{a}} / \tilde{\mathrm{e}}$ & $\tilde{\mathrm{a}} / \tilde{\mathrm{a}}$ \\
\hline$\tilde{\mathrm{I}}$ & $\tilde{1}$ & $\tilde{1}$ & $\tilde{1}$ & $\tilde{1}$ & $\tilde{\mathrm{e}}$ \\
\hline$\tilde{t}$ & $\tilde{I}$ & $\tilde{z}$ & $\tilde{I}$ & $\tilde{\mathfrak{t}}$ & õ \\
\hline uma & uma & uma & uma & uma & duas \\
\hline- & topẽ & topẽ & topẽ & topẽ & - \\
\hline
\end{tabular}

Sobre o ponto 17, adiante apresentamos informações e nossa discordância da autora.

\footnotetext{
${ }^{27}$ Wiesemann emprega um símbolo distinto para a fricativa interdental. Para a africada $\check{c}$ emprega uma forma ortográfica $(c)$, o mesmo acontecendo com a fricativa $\check{s}$ (representada por $s$ ) e com as vogais $/ \supset /(=\dot{o})$ e $/ \tilde{\imath} /(=\tilde{y})$.
} 


\section{Alguns Radicais Jê}

Trabalho pioneiro, metódico e rigoroso, o estudo de Mattoso Câmara Jr. seleciona 30 termos da lista padrão de 200 itens sugerida por Morris Swadesh ${ }^{28}$, recaindo a escolha sobre aqueles termos "...cuja frequência é bastante grande para permitir um trabalho comparativo entre várias línguas..." (Câmara Jr. 1959:6), buscando “...circunscrever o estudo ao exame das listas mais fidedignas, e de maior rigor fonético, obrigou a se restringir o número de línguas, incluindo-se apenas aquelas para as quais há listas nas condições colimadas..." (Câmara Jr. 1959:6), que são, com as respectivas fontes ${ }^{29}$ :

Akroá (Martius 1867), Apinayé (Snethlage 1931), Kayapó do Norte (Ehrenreich 1894; Krause 1911; Nimuendajú 1932), Krahó (Snethlage 1931; Shell 1952), Kren-yé (Nimuendajú 1915), Mehin (Nimuendajú 1915), Pikobié (Snethlage 1931), Rankokamekra (Nimuendajú 1915; Snethlage 1931), Suyá (Steinen 1886), Tayé (Nimuendajú 1914; 1915), Xavante (Ehrenreich 1895), Xerente (Ehrenreich 1895; Nimuendajú 1929).

A tabela abaixo apresenta os 30 termos escolhidos por Mattoso, com as respectivas formas propostas ou reconstruídas (às vezes, mais de uma) para o radical pelo autor, e as formas fonéticas para os termos equivalentes em Xokléng e em Kaingáng, para comparação.

Quadro a partir de Alguns Radicais Jê, de Mattoso Câmara Jr. ${ }^{30}$

\begin{tabular}{|c|c|c|c|c|}
\hline Português & $\begin{array}{l}\text { Radical } \\
\text { reconstruído }\end{array}$ & $\begin{array}{l}\text { Língua mais } \\
\text { próxima }^{32}\end{array}$ & Xokléng & Kaingáng PR \\
\hline 01. Boca & ARKWA & Rankokamekra & jãnt'ki & jẽnt'ki \\
\hline & TAWA & Akroá & & \\
\hline 02. Cabeça & $\begin{array}{l}\text { KRAN } \\
S^{\prime} \ddot{U}(N),\end{array}$ & $\begin{array}{l}\text { Akr. Kay. Xe. } \\
\text { Tayé }\end{array}$ & $\mathrm{kl} \tilde{\varepsilon}$ & kï \\
\hline 03. Cabelo & $\begin{array}{l}{ }^{*} \mathrm{KHIN} \\
\mathrm{S}^{\prime} \ddot{\mathrm{U}}(\mathrm{N})\end{array}$ & Tayé & kə'ki & ki'ki \\
\hline 04. Dente & $\begin{array}{l}\text { KWA } \\
\text { *TS'HWA }\end{array}$ & Akr. Xa. Xe. & ja & jã \\
\hline 05. Língua & РTO & $\begin{array}{l}\text { Krahó, } \\
\text { Rankokamekra }\end{array}$ & nũ'nã & nũ'ñ \\
\hline 06. Mão & *BKHRA & & nẽ' & nĩ'ฤع \\
\hline
\end{tabular}

\footnotetext{
${ }^{28}$ Morris S. (1955) Towards Greater Accuracy in Lexicostatistic Dating. IJAL, vol. 21 (2), p. 121-137.

${ }^{29}$ As fontes relacionadas nessa passagem não constam em nossa bibliografia, a não ser as que, eventualmente, sejam citadas diretamente por nós.

${ }^{30}$ Língua indicada por Mattoso, em cada caso, como a base do radical proposto. Quando a forma proposta é reconstruída como uma protoforma, o autor marca com asterisco.
} 


\begin{tabular}{|c|c|c|c|c|}
\hline 07. Nariz & *KHRA & & nẽ'jã & nî̉j $\tilde{\varepsilon}$ \\
\hline 08. Olho & NTO & $\begin{array}{l}\text { Kre. Me. Pi. Ra. } \\
\text { Ta }\end{array}$ & ko'nã & ka'ñ \\
\hline 09. Orelha & $\begin{array}{l}\text { *MPAK } \\
\text { KAIKAU }\end{array}$ & Suvá & nẽ'’’lãy & 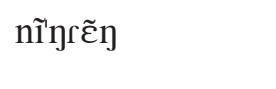 \\
\hline 10. Perna & $\begin{array}{l}\text { KAIKAU } \\
\text { TA }\end{array}$ & $\begin{array}{l}\text { Ap. Kay. Kra. } \\
\text { Ra. Xa. }\end{array}$ & jo & fa \\
\hline 11. Pé & PAR & Kay. Kra. Pi. & pãn & $\mathrm{p} \tilde{n} \mathrm{n}$ \\
\hline 12. Pescoço & $\begin{array}{l}\text { MPUT } \\
\text { NKRA }\end{array}$ & $\begin{array}{l}\text { Tayé } \\
\text { Apinayé }\end{array}$ & "nduj & "'ndujf' \\
\hline 13. Sangue & $\begin{array}{l}\text { *KAMPRU } \\
\text { *WAPRU }\end{array}$ & & kə'vعj & kig'vejj’ \\
\hline 14. Água & $* \mathrm{NKO}$ & & "ygojo & “"ygojo \\
\hline 15. Céu & $\begin{array}{l}\text { *KATIKWA } \\
\text { HAIÑUA } \\
\text { HÖWA }\end{array}$ & $\begin{array}{l}\text { Xavante } \\
\text { Akroá }\end{array}$ & kojc'ka & kajc ${ }^{`} k a ̃ ~(\sim k a j t k a ̃)$ \\
\hline 16. Chuva & *NTAÑ & & to & ta \\
\hline 17. Fogo & $\begin{array}{l}* \mathrm{KUKI} \\
* \mathrm{KUWI} \\
* \mathrm{KUHI}\end{array}$ & & $\mathrm{p} \tilde{\varepsilon}$ & pĩ \\
\hline 18. Frio & *KRÏ & Kayapó & $\begin{array}{l}\text { ku'krili } \\
\text { (geada, gelo) }\end{array}$ & $\begin{array}{l}\text { ku'kriri } \\
\text { (geada, gelo) }\end{array}$ \\
\hline & тÖ & Akroá & & \\
\hline 19. Pedra & *KHA:N & & ko'di & po \\
\hline 20. Sol & $\begin{array}{l}\text { *MPUT } \\
\text { *AMKHRO }\end{array}$ & & la & rã \\
\hline 21. Terra & $\begin{array}{l}\text { *PYË } \\
\text { *PYËKA } \\
\text { TIKA }\end{array}$ & & jgo & jga \\
\hline 22. Cão & *ÏROP & & ka'čolo & $\begin{array}{l}\text { hog'hog' } \\
\text { (tb. ka'tforo) }\end{array}$ \\
\hline 23. Peixe & TA:P & Kay. Ap. Pi. Ra. & ka'klo & pi'rã \\
\hline 24. Cobra & $\begin{array}{l}\text { *KAÑOÑ } \\
\text { WAHI } \\
\text { MAKE }\end{array}$ & $\begin{array}{l}\text { Xavante } \\
\text { Xerente }\end{array}$ & põn & pãn \\
\hline 25. Branco & $\begin{array}{l}* \mathrm{KA}(\mathrm{N}) \\
\mathrm{KUKE} \\
\mathrm{TIB}\end{array}$ & $\begin{array}{l}\text { Piokobié } \\
\text { Kayapó }\end{array}$ & ku'pli & ku'pri \\
\hline 26. Bom & $\begin{array}{l}\text { MPA: } \\
\text { PSE }\end{array}$ & $\begin{array}{l}\text { Rankokamekra } \\
\text { Xerente }\end{array}$ & $\mathrm{u}$ & hə \\
\hline
\end{tabular}




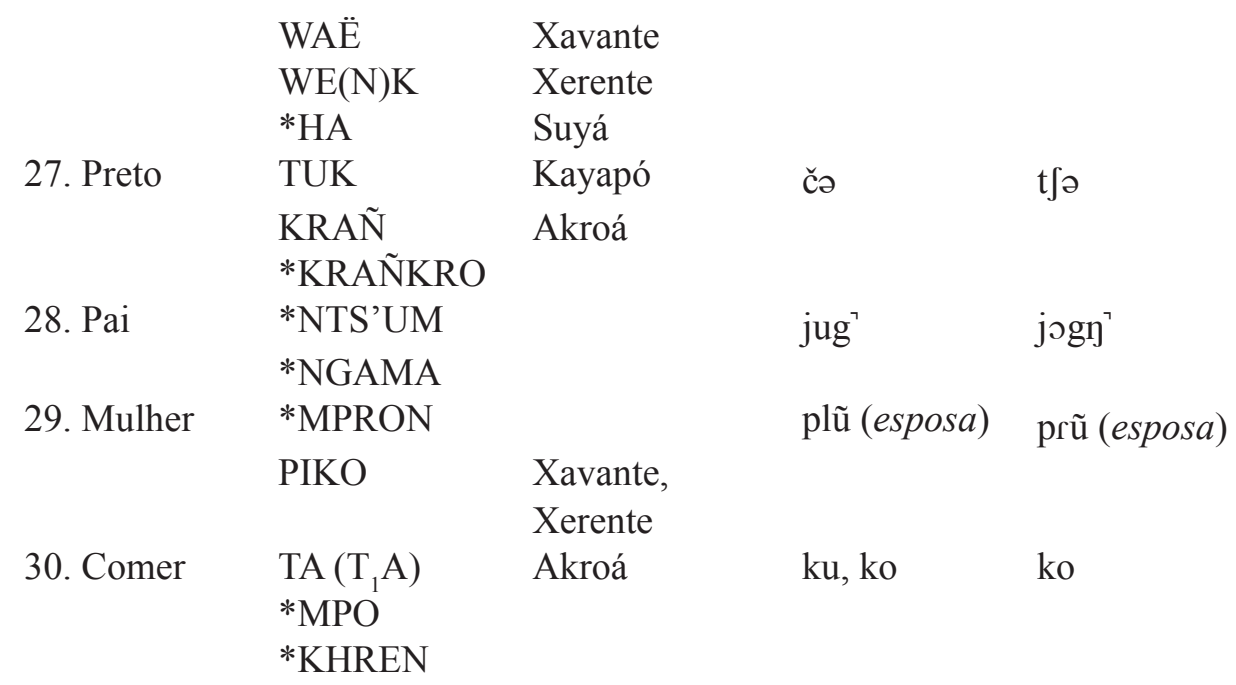

A observação atenta do quadro não permite reconhecer mais do que sete radicais como a fonte ou origem segura de palavras atuais do Xokléng e do Kaingáng $(02,11,14,15,16,18 \text { e 29) })^{31}$. Em outros cinco essa origem é razoavelmente provável $(03,06,08,13$ e 21$)$ e em outros 2 (04 e 27) remotamente possível. Dizendo de outra forma, em pelo menos $50 \%$ do conjunto de itens reunidos por Mattoso Câmara não há a mínima possibilidade de relação entre a forma do radical Jê e a forma atual das línguas Jê Meridionais. Como veremos, adiante, Davis (1966) chamará a atenção para a contribuição menor do Proto-Jê ao léxico do Kaingáng, em relação às línguas Jê Centrais e Setentrionais.

Uma das conclusões importantes de Câmara Jr., segundo ele mesmo salienta, é a da "existência primária de oclusivas pré-nasalizadas, que explicam certas divergências de um mesmo radical, de língua para língua" (Câmara Jr. 1959:65).

Mais relevante, ainda, é o esforço de Mattoso na "tentativa de distribuição classificatória das 12 línguas consideradas, dentro do bloco Jê, em bases puramente linguísticas", ao contrário, como diz, do que se tinha feito até então (Câmara Jr. 1959:65). Para isso, toma em conta 3 aspectos linguísticos: "1) o uso preferencial de dados afixos; 2) as mudanças fonéticas preferenciais; 3 ) as asociações e separações entre radicais e variantes de radicais" (Câmara Jr. 1959:65).

\footnotetext{
${ }^{31}$ Como veremos adiante, Davis reconstrói, para "boca", a forma *zaz-kwa, que se mostra compatível com as formas do Xokléng e do Kaingáng.
} 
Mattoso constrói, assim, o quadro de distribuição e parentesco genético abaixo, com a ressalva de que "é verdade que essa distribuição não é absoluta, e, uma ou outra vez, vemos o Ap. e Pi. se aproximarem do grupo Ak. Xa. Xe. (...) ou o Ta. se relacionar com o Su." (Câmara Jr. 1959:67).

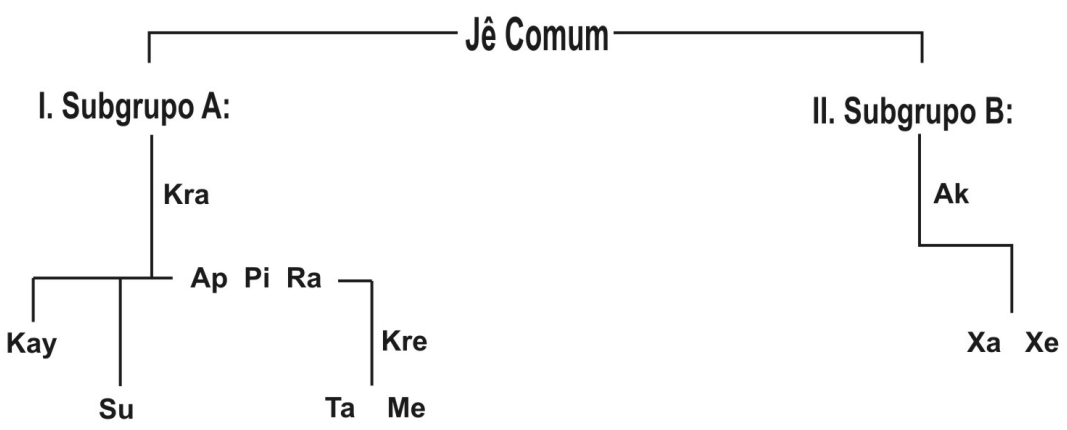

(Câmara Jr. 1959:67)

Como destaca o próprio autor,

...a divisão dos subgrupos A e B coincide com o que fazem Schmidt, Mason e mesmo, dentro de um critério puramente geográfico, Loukotka (...). Mas a divisão interna em cada subgrupo, especialmente em A, parece inteiramente nova, e além de tudo se obtém uma distribuição na base do grau de evolução da estrutura linguística. (Câmara Jr. 1959:68).

Como vimos, Mattoso não trabalhou com dados de nenhuma língua Jê Meridional, e por essa razão elas não aparecem no esquema acima. O quadro resumo que apresentamos, no entanto, cotejando o trabalho de Mattoso com dados do Xokléng e do Kaingáng, e a análise que fizemos dele, mostra um forte distanciamento dessas línguas em relação às Jê Centrais e Setentrionais, distanciamento bastante maior do que aquele observado entre os subgrupos A e B do esquema acima. Em outras palavras, com base no observado, poderíamos sugerir um esquema mais amplo, embora simplificado, com essa configuração (subentendendo, sem discussão - por ser irrelevante para o caso - a organização interna dos subgrupos, proposta em Câmara Jr. 1959):

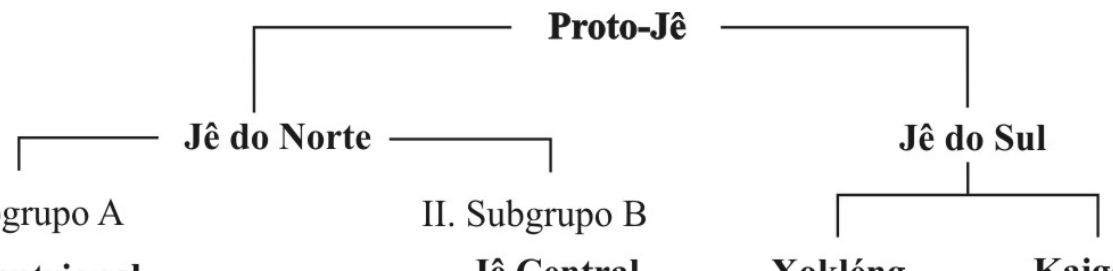




\section{Comparative Jê Phonology}

O artigo de Irvine Davis, Comparative Jê Phonology, certamente contribuiu para o incentivo e interesse pela área em nosso país, já que, até então, pouquíssimos eram os trabalhos de reconstrução de protolínguas, envolvendo famílias linguísticas indígenas.

Para realizá-lo, Davis empregou dados de pesquisas sobre as línguas Apinayé, Canela, Suyá, Xavante e Kaingáng. ${ }^{32}$ Apinayé é representante de línguas Jê Setentrionais, e se aproxima bastante do Mebengokrê (Kayapó), apesar das particularidades dessa última ${ }^{33}$. Canela representa, dentre as línguas Setentrionais, o subgrupo das línguas Timbira Orientais. O Suyá representa línguas Jê Setentrionais mais a Oeste, e o Xavante, as Jê Centrais. Por fim, o Kaingáng (dialeto do Paraná, com dados de Wiesemann), representa, nesse trabalho, o ramo Jê Meridional.

$\mathrm{O}$ autor destaca que a língua Kaingáng

...tem sido algumas vezes classificada como pertencente à família Jê, e outras vezes como constituindo uma família ligada ao tronco Macro-Jê (...). Quando comparado com as línguas Jê tradicionais, o Kaingáng mostra em torno de $40 \%$ de cognatos no vocabulário básico de 100 palavras. Isso o situaria dentro da família Jê, de acordo com a escala de classificação sugerida por Swadesh..$^{34}$ Não obstante, o Kaingáng permanece - com base na similaridade lexical - mais propriamente como um membro divergente da família, uma vez que a taxa de cognatos entre as tradicionais línguas Jê revela percentuais em geral acima de $60 \%$.

Para os propósitos de reconstrução fonológica, a língua Kaingáng integra-se mais logicamente com a família Jê do que como uma família separada dentro do tronco Macro-Jê. Ela está, obviamente, mais estreitamente relacionada com as tradicionais línguas Jê do que outras línguas Macro-Jê, com o Maxakalí, e em muitos aspectos, ela apresenta maior semelhança com a fonologia do Proto-Jê do que o Xavante, um incontestável membro da família. (Davis 1966:10-11) ${ }^{35}$.

\footnotetext{
${ }^{32}$ Como esclarece o autor, à nota 3 (p. 11), os dados de Suyá provieram de pesquisas de Harald Schultz e deVaughn Collins; das demais línguas, de coletas por linguistas-missionários do SIL, ao qual Davis também estava filiado.

${ }^{33}$ Ver D'Angelis, 2002a.

${ }^{34}$ Morris Swadesh, "Towards a satisfactory genetic classification on Amerindian languages", Anais do XXXI Congresso Internacional de Americanistas 1001-1002 (1955). (Nota do original).

${ }^{35}$ Todas as citações de Davis são tradução nossa.
} 
Comparando um vocabulário de 112 itens, e realizando as reconstruções de fonemas, um a um, Davis (1966:13) reconstitui o seguinte sistema consonantal para o Proto-Jê:

$\begin{array}{llll}\mathrm{p} & \mathrm{t} & \mathrm{c} & \mathrm{k} \\ \mathrm{m} & \mathrm{n} & \tilde{\mathrm{n}} & \mathrm{j} \\ \mathrm{v} & \mathrm{r} & \mathrm{z} & \end{array}$

Para as vogais, Davis reconstitui os seguintes conjuntos (1966:13):

$\begin{array}{cccccc}\mathrm{i} & \dot{\mathrm{i}} & \mathrm{u} & \tilde{\mathrm{i}} & \tilde{\mathrm{i}} & \tilde{\mathrm{u}} \\ \mathrm{e} & \partial & \mathrm{o} & \tilde{\mathrm{e}} & \tilde{a} & \tilde{o} \\ \varepsilon & \mathrm{a} & 0 & & & \end{array}$

Seguem-se, aos quadros acima, as seguintes observações:

Nenhum traço suprassegmental foi reconstruído. A posição do acento é previsível ou muito perto disso, nas línguas Jê atuais, e provavelmente não era fonêmica em Proto-Jê. Vogais longas e, possivelmente, consoantes longas eram traços fonêmicos em algumas das línguas Jê. Uma vez que as condições de seu desenvolvimento não são claras, as evidências são insuficientes para postular uma ou outra como traço de um Proto-Jê. (Davis 1966:13).

\subsection{Protofonemas (Jê) consonantais em Davis}

Nas reconstruções de Davis, dos protofonemas consonantais, destacamos os seguintes comentários a respeito do Kaingáng (abreviado como $K a$, em Davis) em relação às demais línguas Jê analisadas e ao protofonema proposto em cada caso ${ }^{36}$ :

*t - "É mantido em Ka, exceto nos itens 66 e 98, que mostram um inexplicado n, e no item 65, que tem r." (Davis 1966:13).

Os dados mencionados na passagem acima são, na ordem citada ${ }^{37}$ :

\footnotetext{
${ }^{36}$ Aqui estamos destacando apenas os comentários que sugerem algum distanciamento ou particularidade do Kaingáng com respeito ao protofonema em questão; nos casos em que o Kaingáng comporta-se conforme as demais línguas e corrobora o protofonema proposto, não há porque destacarmos.

${ }^{37}$ Os dados tirados de Davis são aqui apresentados na forma original do artigo, distinta da forma da publicação, tomando por base as informações de Aryon Rodrigues (editor), em nota de rodapé à página inicial (p. 10) do texto. Por exemplo, substituem-se os $n^{y}$ por $\tilde{n}$, as vogais seguidas de $n$ na sobrelinha por vogal com til, etc. Em Davis, “...o símbolo $c$ é usado para indicar uma africada surda, que tanto pode ser alveolar quanto alveopalatal.” (Davis 1966:12).
} 
66. * $\tilde{n} \tilde{o}-t o$ 'tongue' (língua). Ka nũnẽ

98. *tu, tum 'belly' (barriga). Ka nū

65. ñot, „๊orr 'to sleep' (dormir). Ka nũrũ (cf. Davis 1966:22 e 23)

*c - "Em Ka torna-se ñ em posição final de palavra ou antes de outra consoante $(5,19,20)$ e j em outras posições $(2,4,49,69,110,111)$." (Davis 1966:22 e 23).

Na ordem mencionada, os dados são:

5. *i-, ic- 'my' (meu). Ka Piñ ${ }^{38}$

19. *kəckwa 'sky' (céu). Ka kañkã

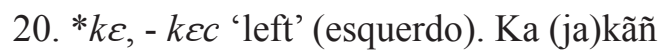

2. *ca, cam 'to stand' (levantar, por em pé). Ka jẽ, jẽ̃

4. *cwa 'tooth' (dente). Ka jã

49. *mrs, mræc, prə 'ashes' (cinzas). Ka mrẽjẽ

69. * „oo, noc 'water' (água). Ka. nojo

110. *zici 'name' (nome). Ka jiji

111. *zo, zoc 'leaf' (folha). Ka feje (cf. Davis 1966:20-23).

Para os dados acima, ao que parece, a melhor descrição em Davis teria sido: no Kaingáng, $\mathrm{o}{ }^{*} c$ torna-se $n$ em posição final de sílaba, e $j$ em posição inicial.

*k - "Ka apresenta $k$ como um reflexo bastante regular de * $k(\ldots)$, apesar de que alguns poucos itens mostram um inexplicado $\eta(8,24,86)$ e os itens 25 e 101 sugerem que o *k final de palavra foi perdido" (Davis 1966:14) ${ }^{39}$. É interessante destacar, a respeito da reconstrução de * $k$, além disso, o que Davis observa a respeito de outras línguas Jê: o fato de que, em Canela e em Suyá, ${ }^{*} k$ "...é duplamente refletido, como $k$ e $k^{\mathrm{h}}$, apesar de que as condições para o desenvolvimento de $k^{\mathrm{h}}$ são diferentes nas duas línguas." (Davis 1966:13). Davis sugere que o acento tenha sido fator determinante para a distribuição

\footnotetext{
${ }^{38}$ É importante observar que, por um processo fonológico comum a línguas Jê e Macro-Jê (ver D’Angelis 1998), a consoante soante nasal palatal / $/ \mathrm{h} / \mathrm{em}$ coda, no Kaingáng, passa a obstruinte palatal surda quando seguida de consoante obstruinte na sílaba seguinte. E, no caso da obstruinte que a segue ser a coronal $[t]$, desse encontro resulta uma fricativa [ [] nos dialetos do Paraná e do Sul, e uma africada $[t]]$ no dialeto de São Paulo e no Xokléng.

${ }^{39} \mathrm{O}$ dado 25 (termo para wind = 'vento') deve ser excluído das exceções ou 'casos problema', listados por Davis, porque no seu vocabulário comparado ele adotou a forma $k \supset(h u)$ para o Kaingáng, tendo reconstruído *kok para o Proto-Jê a partir das demais línguas. No entanto, $k \supset h u$ é o termo Kaingáng para 'vento forte, ventania', enquanto o termo para 'vento' é $k \tilde{a} k a(\mathrm{PR})$ ou $k \tilde{k} k a(\mathrm{Sul})$, que mantém o segundo $* k$.
} 
das variantes aspirada e não aspirada, uma vez que, com poucas exceções, $k^{h}$ ocorre no onset de sílaba final de palavra ("a sílaba que é normalmente acentuada"), enquanto k aparece em onset das outras sílabas, e em posição final de palavra (Davis 1966:13-14). Ainda sobre o Kaingáng, a 'sugestão' (pelos itens 25 e 101) de que o *k final de palavra teria se perdido, não é isso que nos parece. No dado 25 , a reconstrução feita para o item lexical é *kok 'wind' (vento), mas para o Kaingáng, Davis usa o termo $k s(h u)$, que apenas no dialeto paulista tem esse significado; nos demais, significa 'vento forte' ou 'tempestade'. Para "vento" simplesmente, os dialetos do PR e do Sul empregam kõka, e o que se vê é uma ressilabificação do * $k$ reconstruído. Já o dado 101, efetivamente pode representar uma perda da consoante final, da protoforma *ty, tyk, tyr para o Kaingáng $(k u) t y$ (nesse caso, talvez, pela precedência de uma vogal dorsal alta).

? - Davis não reconstrói um protofonema / P/, antes o contrário. É importante, pois, conhecer sua conclusão a respeito. Escreveu ele:

Uns poucos itens nos presentes dados mostram consoantes que, aparentemente, não são reflexos diretos de qualquer fonema ProtoJê. Isso inclui o surgimento de uma oclusiva glotal em Xa e Ka precedendo o que foi reconstruído como uma vogal inicial $(1,5)^{40}$, e em Apinayé e Canela precedendo certas consoantes mediais (39, 62, 66). (...) Os dados são insuficientes para quaisquer conclusões acerca desses desenvolvimentos. (Davis 1966:15-16).

$* \mathbf{m}-$

Em Ka a maioria das ocorrências de * $m$ final de palavra tem se tornado $\eta(2,91,98,102)$, apesar de que * $m$ mantém-se no item 37 e, aparentemente, tornou-se n no item 24 . Em outras posições, * $m$ tem-se regularmente mantido $(42,43,46-49,52,54)$ exceto no item 44, que mostra um inexplicado $p$. (Davis 1966:14) . $^{41}$.

Em Ka * $n$ é mais geralmente mantido $(54,56-58)$, mas aparece como t nos itens 55 e 59 (Davis 1966:14). Os dados 'discrepantes' são esses (na íntegra):

\footnotetext{
${ }^{40}$ Os exemplos em questão, que interessam em particular ao Kaingáng, são: "1. * $a$ - your. Ap $a$-, Ca $a$-,

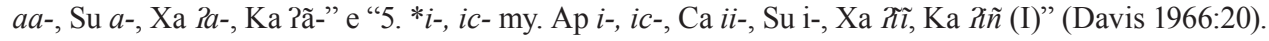

${ }^{41} \mathrm{O}$ dado 44 não é exceção, como pensou Davis. Trata-se do termo para o qual deu a tradução to throw = 'lançar', 'atirar', 'arremessar'. Davis o reconstrói como *mẽ ,*mẽn, mas para o Kaingáng apresenta a forma $p \tilde{e} \eta=$ to shoot $=$ 'chutar'. No entanto, o mais correto seria a comparação com min $=$ 'despejar', no dialeto do Paraná (cf. Wiesemann 2002:118).
} 
55. *na 'rain'. Ap na, Ca taa, Su naa, Xa tã, Ka ta. ${ }^{42}$

59. *nyw 'new'. Ap nyw, Ca -tuwa, Su nywy, Xa - te, Ka tãy

(Davis 1966:22)

$* \mathrm{n}-$

...ñ é reconstruído, no final de palavra, em formas alternantes de vários itens. Nessa posição ele é refletido regularmente como $\tilde{n}$ em Ap e Xa e como $\eta$ em Ka $(8,28,39,44,47,50,86,99$, 107). (...) Um item (46) foi reconstruído com $\tilde{n}$ final (...) Esse item mostra $\tilde{n}$ em Ap, mas $n$ como reflexo tanto em Su como Xa, e $\eta$ em Ka. (...) Uma descrição das condições de alternância morfofonêmicas vai além do escopo do presente trabalho (...) Em Ka ele aparece como $j$ antes de $\tilde{e}(60,63,64)$ e como $n$ em outros lugares (62, 63, 65-67). (Davis 1966:15-16).

$* \mathbf{z}-$

...exibe uma grande variedade de reflexos e suas características fonéticas originais não são conhecidas (...). Em Ka $*$ tornou-se ou $j(104,106,108,110)$ ou $f(39,105,111,112)$ em posição inicial, e tornou-se $h$ (16) ou $j$ (35) em posição intervocálica. As condições para o desenvolvimento distinto não são claras. Seguindo uma consoante, é refletido como zero (54) e precedendo uma consoante, como $n(33,108)$. (Davis 1966:15).

Observemos os dados relacionados por Davis (parágrafo anterior) para discutir os reflexos do protofonema $* z$ no Kaingáng (acrescentamos, à direita, o correspondente em Xokléng):

Davis (1966:21-23)

PR (Wiesemann) Xokléng
(forma fonética)
104. *zako, zakor 'to blow' (soprar). Ka jãka $=$ [kijã'ka $\quad$ Xo: kizakə $=[\mathrm{kiða'kə]}$
106. *za-re 'root' (raiz). Ka jãre
$=[$ jã're $] \quad$ Xo: jãle
108. *zaz-kwa 'mouth' (boca). Ka jẽnki = = jẽnt'ki] Xo: jãnki
110. *zici 'name' (nome). Ka jiji = $\quad$ [ji'ji $\quad$ Xo: jiji

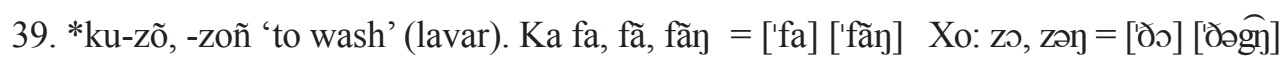

\footnotetext{
${ }^{42} \mathrm{Ap}=$ Apinayé, $\mathrm{Ca}=$ Canela, $\mathrm{Su}=$ Suyá, $\mathrm{Xa}=$ Xavante, $\mathrm{Ka}=$ Kaingáng.
} 


\begin{tabular}{|c|c|c|}
\hline 105. *za-re wing, 'feather' (asa, pena). Ka f & $=[\text { 'fẽẽ̃̃ }]^{43}$ & Xo: zãl = ['ðãlã $]$ \\
\hline 111. *zo, zoc 'leaf' (folha). Ka feje & $=\left[{ }^{\prime} f \varepsilon j \varepsilon\right]^{44}$ & $\mathrm{Xo:} \mathrm{z \varepsilon j}=\left[{ }^{\prime} \partial \varepsilon j \varepsilon\right]$ \\
\hline 112. *zy 'seed' (semente). Ka fï & $=[$ 'fit $]$ & Xo: zi \\
\hline 16. *ka-zo, -zor 'to suck' (chupar). Ka kãhun & $=[$ kã'hudn $]$ & Xo: kahun \\
\hline 35. *ku-koz ‘monkey’ (macaco). Ka kajẽ(rẽ) & $=[\mathrm{ka} \tilde{\jmath} \tilde{\mathrm{e}} \tilde{\mathrm{e}} \tilde{\mathrm{e}}]^{45}$ & Xo: kəjãl = [ko'jãlã $]$ \\
\hline 54. *mzen 'husband' (marido). Ka men & $=[$ 'mbedn $]$ & Xo: $\mathrm{m} \varepsilon \mathrm{n}=[$ 'mbे $\widehat{\mathrm{dn}}]$ \\
\hline 3. *kriz 'parrot' (papagaio). Ka krĩn (krĩrĩ) & $=\left[\mathrm{krip}{ }^{\prime} \mathrm{kr}\right.$ & 46 Xo: ?? \\
\hline
\end{tabular}

A informação que introduzimos, sobre as formas fonética e fonológica em Wiesemann (fonte dos dados de Davis), permite-nos buscar esclarecer as condições de produção da distinção entre $f$ e $j$, encontrada no Kaingáng, a partir do protofonema $* z$. A informação sobre as respectivas formas em Xokléng, como veremos, mostra-se igualmente útil para esse esclarecimento.

Olhando para o Kaingáng do Paraná, vemos que em 104, 106, 108 e 110 o reflexo $j$ ocorre em sílaba átona ${ }^{47}$, enquanto em $39,105,111$ e 112 , o reflexo $f$ ocorre em sílaba tônica. ${ }^{48}$ No Xokléng essa distribuição fica parcialmente prejudicada, porque em 104 encontramos $*_{z}: z$ (e não $*_{z}: j$ ) em uma sílaba átona. Apesar disso, estando correta a reconstrução de Davis para o protofonema $*_{z}$, é mais plausível a hipótese em a):

\footnotetext{
${ }^{43} \mathrm{Em} 105$, o que Davis registra é propriamente a forma fonética, uma vez que a vogal final, nesse tipo de item lexical, é uma 'cópia' da vogal da sílaba. Observe-se a posição do acento. A forma fonológica, em 105, é /fẽr/. De fato, o próprio Davis observara isso, e situações semelhantes em outras das línguas analisadas, como se lê nas seguintes passagens do seu texto: "Em um grande número de itens que foram reconstruídos com uma consoante final, aparecem, em algumas línguas, uma vogal seguindo a consoante. Não é claro, quantas dessas vogais representam um efetivo desenvolvimento fonêmico e quantas são resultado de percepção e interpretação diferente de dados fonéticos de parte dos investigadores. Muitas ocorrências de vocóides finais nas línguas Jê são de estatuto fonêmico duvidoso (...). Ka mostra o desenvolvimento de uma vogal final seguindo $w, j$ e $r$, que é idêntica à vogal imediatamente precedente à consoante (...)" (Davis 1966:16-17).

${ }^{44} \mathrm{Em} 111$ temos uma situação semelhante à de 105 (ver nota anterior). Aqui, a forma fonológica é $/$ fgj/.

${ }^{45}$ Em 35, outra situação semelhante à de 105 (ver notas anteriores). Em 35 a forma fonológica é /kajẽr/.

${ }^{46}$ Esse termo (razoavelmente distinto daquele que Davis utiliza) aparece no Dicionário de Wiesemann (2002:53) com a tradução: Papagaio do Reino. Essa denominação, porém, não comparece em manuais de ornitologia. Para "papagaio", simplesmente, o termo Kaingáng no PR e Sul é /jonjo/. A forma citada por Davis (não localizamos o documento de sua fonte) distancia-se da protoforma reconstruída pelo fato de contar com vogais nasais, e aproxima-se mais, no Kaingáng, de kĩnkrĩr, araguai (Wiesemann 2002:52).

${ }^{47}$ Em 110 ocorre nas duas posições, mas é evidentemente um caso de palavra com reduplicação.

${ }^{48}$ No Xokléng essa distribuição fica parcialmente prejudicada, porque em $104,{ }^{*} z: z$ (e não $*_{z}: j$ ) em uma sílaba átona.
} 


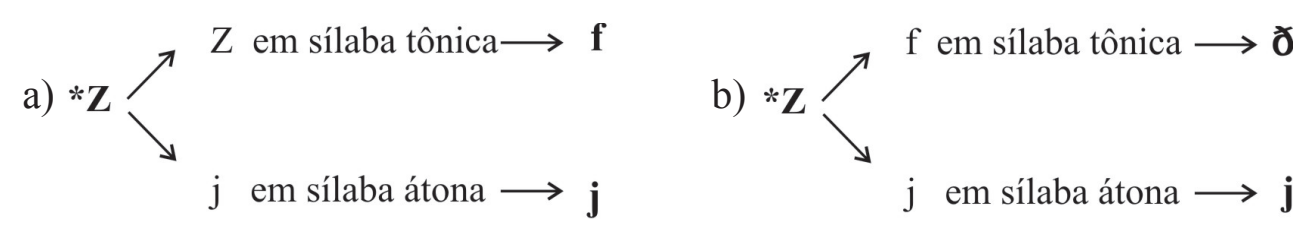

Isso significa assumir que o Xokléng, nesse aspecto, está mais próximo do Proto-Jê (portanto, é mais conservador) que o Kaingáng.

Entre 16 e 35 talvez não seja correta a relação que o autor estabelece. Enquanto o dado 16 representa, de fato, uma situação intervocálica de ocorrência do reflexo $h$ do protofonema ${ }^{*} z$, em 35 talvez se tenha tido, historicamente, uma posição de coda silábica, no estágio em que se deu a passagem $*_{z}>j$. Se tomarmos em conta o Xokléng e a forma reconstruída por Davis, parece

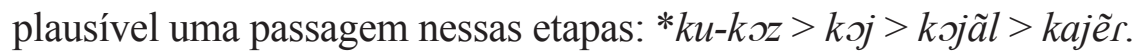

Em 54 temos uma situação única, nas reconstruções para o Proto-Jê, de uma sílaba com onset complexo *mz. Obviamente isso significa uma palatalização, que é o que se preservou no termo Apinayé (e Mebengokre) mjen, no Canela pje, e no Suyá mjeni. No Kaingáng e no Xokléng o encontro foi desfeito, efetivamente, sem substituição por outro, permanecendo a primeira consoante (no caso, com realização fonética complexa, devido à vogal oral da sílaba, que também exige uma realização complexa da consoante que trava a sílaba): ['mbै $\widehat{m d n}]{ }^{49}$

Sobre o dado 33 (último da tabela acima), Davis fala em um reflexo $n$, mas o dado mais preciso, tomado em Wiesemann (2002), mostra um reflexo $j$ ou $n$ (um em cada uma das sílabas reduplicadas), condizente com a interpretação que propusemos para o dado 35 .

\subsection{Proto-fonemas (Jê) vocálicos em Davis}

Nas reconstruções de Davis, dos protofonemas vocálicos, destacamos os seguintes comentários a respeito do Kaingáng: $* \mathbf{y}-$

...é refletido com considerável regularidade como ə em Xa e como $y$ nas outras línguas $(32,33,36,40,41,52,53,59,84-$ $86,90,100,101,112)$, apesar de existirem vários exemplos de vogais anteriores Ka como um reflexo de * $y(33,85,100)$ (Davis 1966:16).

\footnotetext{
${ }^{49}$ Registre-se um outro caso de palatalização no Apinayé que, no Kaingáng, corresponde a um encontro consonantal: Ap. $k j \hat{e}=$ coxa Ka. $k r e$. (Apinayé cf. Albuquerque 2007:43).
} 
Da longa relação de exemplos, apenas 32, 52, 84, 101 e 112 dizem respeito ao Kaingáng, e apresentam a correspondência * $y: y$, além de 33, 85 e 100, destacados por ele como um certo problema. Para o dado 33, já vimos acima que Davis relacionou a forma por ele reconstruída *kriz ('parrot' = papagaio) com Ka krĩn (krĩrĩ), mas a forma adequada, em Wiesemann (2002) é [krijnkrijj]. Portanto, esse não é um exemplo de vogal anterior, no Kaingáng, como reflexo de $* y$, mas é mais um exemplo da correspondência $* y: y$. Em 85, para o item reconstruído como *py-ci, py-cit ('one' = um) o Kaingáng tem pi (ri), segundo Davis (na verdade, /pir/ = ['piri] ). Em 100, Davis reconstrói *ty, tyk, tyr ('to die' = morrer), enquanto o Kaingáng mostra a forma tere (em Xavante é $t ə$, nəアə, nəəгə, segundo o próprio Davis, e em Xerente, dərə, seg. Krieger \& Krieger 1994).

$* \mathbf{a}-$

...é refletido como ẽ em muitos itens Ka sob condições que não são claras $(2,27,42,43,60,63,74,78,105,108)$; caso contrário, geralmente mantém-se inalterado $(1,2,4,6-16,19,27,42,43,55$, 60, 62, 63, 74-76, 78, 79, 86, 91, 103-108). (Davis 1966:16).

De fato, os 10 primeiros dados relacionados apresentam, de PJ para Kaingáng, a correspondência $* a$ : ẽ. Já os 35 dados em que *a manteve-se "geralmente" inalterado, referem-se ao conjunto das línguas Jê do estudo, mas apenas 13 dizem respeito ao Kaingáng. Abaixo os reproduzimos (apenas para o item reconstruído e a forma em Kaingáng), dispondo em grupos, conforme nossa interpretação (e acrescentando o correspondente Xokléng, para comentar adiante):

\begin{tabular}{|c|c|c|}
\hline Proto-Jê & Kaingáng PR & Xokléng \\
\hline 1. *a- 'your' (seu). & Ka $\mathfrak{\imath a}-$ & Xo $a_{-}-\left(\mathrm{Pa}_{-}\right)$ \\
\hline 4. *cwa 'tooth' (dente). & Kajã & Xo ja \\
\hline 16. *ka-zo, -zor 'to suck' (chupar). & Ka kãhun & Xo kahun \\
\hline 19. *kəckwa 'sky'. & Ka kañkã & Xo konka \\
\hline 104. *zako, zakor 'to blow' (soprar). & Ka jãka & Xo zakə \\
\hline 106. *za-re 'root' (raiz). & Ka jãre & Xo jãle \\
\hline 91. *ta, tam (pronome $3^{a}$ pessoa). & $K a(t i) t \tilde{\partial}, t o \eta$ & Xo ta \\
\hline 55. *na 'rain' (chuva). & Ka ta & Xo to \\
\hline 86. *py-ka, -kañ 'earth' (terra). & Ka па & Хо ฤЈ \\
\hline 13. *kanã 'snake' (cobra). & Ka kakə (wə) & n, 2002:113 - \\
\hline
\end{tabular}

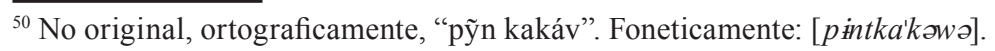


12. *kana 'lazy' (preguiçoso). Ka kana ('sick' = doente)

62. * $\tilde{n} \tilde{l}-k r a$ 'hand'. Ka kra ('pestle' = pilão)

76. *pa, par 'to finish' (terminar). Ka pan ('to throw out' = mandar sair)

O primeiro grupo, com seis dados, na verdade revela uma correspondência $* a: \tilde{a}$. Segue-se o dado 91 , onde vemos a correspondência $* a:$ ã, que pode ser uma variação da anterior.

No terceiro agrupamento, com três dados, efetivamente encontramos a correspondência $* a: a$. Curiosamente, nos dois primeiros casos (dados $55 \mathrm{e}$ 86) a consoante do Proto-Jê não havia se conservado no Kaingáng. O dado 13 apresenta a correspondência $* a: a$ em uma sílaba que também antecede uma consoante não conservada.

Finalmente, o quarto agrupamento reúne dados que nos parecem injustificados. Não parece inquestionável a aproximação pretendida entre os termos preguiçoso e doente, no dado 12 , ou entre mão e pilão (na verdade, kra é mão de pilão), no dado 62; ou, ainda, entre terminar e mandar sair, no dado 76. Aliás, para o referente mão (dado 62), o Kaingáng tem a palavra $n \tilde{\imath} \eta \mathcal{E}=[n \tilde{\imath} n g \varepsilon]$, essa sim, relacionada com a protoforma proposta.

Portanto, os reflexos de * $a$, no Kaingáng, variam entre $\tilde{e}$ (10 dados) e $\tilde{a}$ (7 dados), com alguns poucos casos em que se conservou $a$ ( 3 dados).

É interessante observar as correspondentes formas do Xokléng, para o caso em análise. Em todos os casos em que se dá, entre PJ e Kaingáng, a correspondência * $a: \tilde{e}$, entre PJ e Xokléng a correspondência é * $a: \tilde{a}: 2$. *ca, cam Xo jã $;$; 27. *kra Xo klä; 42. *ma Xo mã; 43. *-ma, -mar Xo -mã;

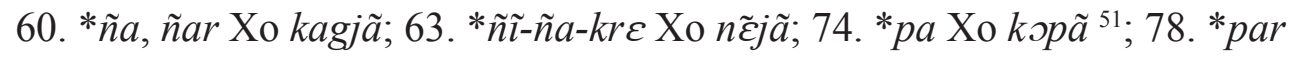
Xo pãn; 105. *za-ra Xo zãl; 108. *zaz-kwa Xo jänki.

Dos sete casos em que o Kaingáng apresenta, com relação ao PJ, a correspondência * $a$ : $\tilde{a}$, apenas no dado 106 o Xokléng também a apresenta. Nos outros seis casos $(1,4,16,19,104$ e 91), o Xokléng apresenta * $a$ : $a$. E nos dois únicos casos indiscutíveis de correspondência * $a$ : $a$ do Kaingáng (55 e 86), o Xokléng apresenta * $a$ : o.

A falta de contextos distintos, que esclareçam as condições de

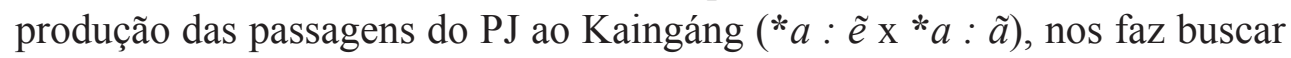
contextos que justifiquem as passagens do PJ ao Xokléng ( $\left.{ }^{*} a: \tilde{a} \mathrm{x} * a: a\right)$.

\footnotetext{
${ }^{51}$ Aqui faço cotejo com o termo para 'galho' $(k o=$ 'pau', 'árvore' $+p \tilde{a}=$ 'braço') (ver Bublitz 1994:5).
} 
A hipótese de que a distinção $* a \mathrm{x} * \tilde{a}$ já estivesse presente, nesses dados, no PJ (o que significaria propor reconstruções distintas daquelas de Davis), não parece razoável, porque em nenhuma das demais línguas elencadas, naquele mesmo conjunto de dados, se observa permanência de nasal (salvo duas exceções $^{52}$ ).

Buscamos, então, no contexto imediato das vogais em questão, a possibilidade de justificativa para os casos em que *a nasalizou-se em Xokléng. Se atentarmos aos dados relacionados dois parágrafos acima (2, 27, $42,43,60,63,78,105$ e 108$)$ encontramos a vogal $* a$ contígua a consoantes nasais em 5 dados $(2,42,43,60$ e 63), situação que não ocorre nos dados em que se dá a correspondência $* a: a(1,4,16,19,104$ e 91$)$. Faltaria justificar, no entanto, porque $* a: \tilde{a} \operatorname{nos}$ dados $27,78,105$ e 108, da relação acima, e também no dado 106, distoante na listagem da correlação * $a$ : $a$. Quando analisamos esses 5 dados em conjunto, observamos, em quase todos eles, a contiguidade da vogal *a com uma líquida: 27. *kra, 78. *par, 105. *za-ra, 106. *za-re. A exceção é o dado 108. *zaz-kwa (no qual, aliás, o Canela tem -jark ${ }^{h} w a$ ), mas esse dado, segundo o próprio Davis, “...é de reconstrução problemática." (Davis 1966:15). Em contrapartida, em todos os casos em que a correlação PJ : Xokléng é * $a: a$, não ocorre contiguidade de * $a$ com líquida. Nossa conclusão é pela hipótese de que vogais contíguas a consoantes nasais e vogais contíguas à líquida, em Proto-Jê, nasalizaram-se na passagem ao Proto-Jê Meridional, ou na passagem do PJM ao Xokléng.

Para concluir essa discussão, comparem-se, abaixo, os dois esquemas, que compõem o seguinte exercício: em (A), simulamos uma passagem do PJ ao PJ-Meridional, em que esse último é representado pelos dados do Xokléng, tomado como língua Jê Meridional mais conservadora; ao contrário disso, em (B) simulamos uma passagem do PJ ao PJ-Meridional, em que esse último é representado pelos dados do Kaingáng do Paraná, tomado - em (B) - como Jê Meridional mais conservador.

(A)

$$
\begin{array}{rll}
\text { PJ } & & \text { PJ-Meridional } \\
* \mathrm{a} & > & * a \tilde{a}(11 \text { dados }) \\
& > & * \mathrm{a}(6 \text { dados }) \\
& > & * 0(2 \text { dados })
\end{array}
$$

(B)

$\begin{array}{cccl} & \text { PJ } & & \text { PJ-Meridional } \\ * \mathrm{a} & > & * \tilde{\mathrm{e}} & (10 \text { dados }) \\ & > & * \tilde{a} & (7 \text { dados }) \\ & > & * \mathrm{a} & (2 \text { dados })\end{array}$

\footnotetext{
${ }^{52}$ As únicas exceções são: o dado 2, Apinayé $c \tilde{m} m$, e o dado 91, Apinayé $t \tilde{\Lambda} m$. O dado do Xavante em 108 , ñañhə (boca), poderia também sugerir suspeita de nasalidade na vogal " $a$ ", pela contiguidade com as nasais palatais, mas o Xavante atual registra (ortograficamente) 'dadzadawa' para esse termo, afastando a possibilidade de nasalização (cf. Hall et al. 1987).
} 
Os contextos que justificariam, em (A), $* a: * \tilde{a}$ e $* a: * a$, seriam os mesmos que em (B) deveriam justificar $* a: * \tilde{e}$ e $* a: * \tilde{a}$. No entanto, se assumirmos a hipótese de que Xokléng e Kaingáng do Paraná representam estágios subsequentes de mudança fonológica no PJM (ou seja, se um dos dois assemelha-se ao estágio anterior do outro) seria mais plausível aceitar $\left(\mathrm{A}_{1}\right)$ do que $\left(\mathrm{B}_{1}\right)$ nas sequências alternativas abaixo:

$\left(\mathbf{A}_{1}\right)$

$\begin{array}{ccccccc}\text { PJ } & & \text { PJ-Merid. } & & \text { Xokléng } & & \text { Kaingáng PR } \\ *_{\mathrm{a}} & > & *_{\mathrm{a}} & > & \tilde{\mathrm{a}} & > & \tilde{\mathrm{e}} \\ & > & *_{\mathrm{a}} & > & \mathrm{a} & > & \tilde{\mathrm{a}} \\ & > & *_{\mathrm{a}} & > & \tilde{\mathrm{a}} & > & \tilde{\mathrm{a}} \\ & > & *_{\mathrm{J}} & > & 0 & > & \mathrm{a}\end{array}$

$\left(\mathbf{B}_{1}\right)$

$\begin{array}{ccccccc}\text { PJ } & & \text { PJ-Merid. } & & \text { Kaingáng PR } & \text { Xokléng } \\ *_{\mathrm{a}} & > & * \tilde{\mathrm{e}} & > & \tilde{\mathrm{e}} & > & \tilde{\mathrm{a}} \\ & > & * \tilde{\mathrm{a}} & > & \tilde{\mathrm{a}} & > & \mathrm{a} \\ & > & * \tilde{\mathrm{a}} & > & \tilde{\mathrm{a}} & > & \mathrm{a} \\ & > & * \mathrm{a} & > & \mathrm{a} & > & 0\end{array}$

Em $\left(\mathrm{B}_{1}\right), * a$ passaria a $* \tilde{e}$, que se conservaria em Kaingáng e, em outro estágio (no Xokléng), passaria a $\tilde{a}$ (isto é, voltaria à qualidade da vogal do $\mathrm{PJ}$, porém nasal). Da mesma forma, $* a$ nasalizaria em $* \tilde{a}$, que se conservaria em Kaingáng, para depois, em Xokléng, voltar a ser oral $a$.

Em contrapartida, em $\left(\mathrm{A}_{1}\right), * a$ passaria a $* \tilde{a}$ (nos contextos descritos), conservando-se no Xokléng, e tornando-se ẽ no Kaingáng. E, nos demais contextos, * $a$ conserva-se $* a$ (do PJ ao PJM), que se mantém no Xokléng, e nasaliza em Kaingáng para $\tilde{a}$. Desfavorável a essa alternativa são apenas os 2 dados em que *a passaria a $*$, conservando-se $\lrcorner$ em Xokléng, para tornar a ser $a$ no Kaingáng.

A análise alternativa a essa é a que assume caminhos distintos e independentes, do PJ-Meridional ao Xokléng e ao Kaingáng.

${ }^{*} O$ e $* \tilde{o}-$ "Em Ka $* \tilde{o}$ é muito frequentemente refletido como $\tilde{u}(48,65,66$, $83)$ ou $\tilde{a}(30,57)$, enquanto $* o$ tem tal variedade de reflexos que nenhuma conclusão pode ser esboçada." (Davis 1966:16). ${ }^{53}$

\footnotetext{
${ }^{53}$ Há um erro no original; o correto seria indicar, no segundo parênteses, os dados 39 e 57 (em lugar de 30 e 57).
} 
* - - “...permanece inalterado, com muito poucas exceções, em cada uma das línguas, exceto Ka. Em Ka é mais frequentemente refletido como ẽ." (Davis 1966:16).

Para concluir a resenha e discussão do importante trabalho de Irvine Davis de que temos tratado, resumimos aqui o tópico 2.5 do mencionado trabalho, iniciado por The Kaingáng phonemes, ao que se seguem efetivamente os quadros fonológicos de vogais e consoantes:

\begin{tabular}{|c|c|c|c|c|c|c|c|c|c|}
\hline \multicolumn{4}{|c|}{ Consoantes } & & \multicolumn{3}{|c|}{ Vogais orais } & \multicolumn{2}{|c|}{ Vogais nasais } \\
\hline p & $\mathrm{t}$ & & $\mathrm{k}$ & $?$ & $\mathrm{i}$ & $\dot{\mathrm{i}}$ & $\mathrm{u}$ & $\tilde{1}$ & $\tilde{\mathrm{u}}$ \\
\hline $\mathrm{m}$ & $\mathrm{n}$ & $\tilde{\mathrm{n}}$ & $\eta$ & & e & $\partial$ & o & & $\tilde{\partial}$ \\
\hline & & $\int$ & & $\mathrm{h}$ & $\varepsilon$ & $\mathrm{a}$ & 0 & $\tilde{\mathrm{e}}$ & $\tilde{\mathrm{a}}$ \\
\hline
\end{tabular}

$\mathrm{Na}$ primeira série consonantal, de oclusivas surdas não-aspiradas, destaque-se o seguinte comentário de Davis: "A oclusiva glotal $/ \boldsymbol{R} /$ é um desenvolvimento especial que aparentemente nunca reflete um fonema segmental Proto-Jê.” (Davis 1966:20).

Na série soante nasal, “...m é regularmente um reflexo de * $m$, enquanto $\mathrm{n}$ pode ser um reflexo de $* n, * t, * \tilde{n}, * r, * z$ e, possivelmente, $* m$. A nasal alveopalatal $\tilde{n}$, por outro lado, aparentemente, é sempre um reflexo de ${ }^{*} c$. A nasal velar $\eta$ pode ser um reflexo de $* \eta,{ }^{*},{ }^{*} m,{ }^{*} \tilde{n}$ e, possivelmente. ${ }^{*} w . "$ (Davis 1966:20).

$\mathrm{Na}$ terceira série das consoantes,

... $|f|$ é uma fricativa bilabial e reflete $* z$. / $/$ é uma fricativa alveopalatal côncava que não é representada no vocabulário comparativo. Sua derivação não é conhecida. $/ h /$ é uma fricativa glotal que parece ser um raro reflexo de $*_{z ; \ldots}$ (Davis 1966:20).

Quanto às vogais,

...o sistema vocálico oral do Kaingáng é o típico sistema de nove vogais das línguas Jê. As vogais frontais e centrais, com exceção de $/ ð /$, da qual há poucos dados, são geralmente derivadas das correspondentes vogais Proto. Existem, no entanto, vários exemplos de $/ a /$ derivado de $* o$. As vogais posteriores $/ u /$ e / / são atestadas por muito poucos exemplos e não é possível estabelecer sua derivação, a não ser que sejam derivadas ou de suas correspondentes vogais Proto ou de protovogais adjacentes. (Davis 1966:20). 
Por sua vez,

...cada uma das cinco vogais nasais exibe mais de uma derivação. A vogal $/ \tilde{\imath} /$ é derivada mais frequentemente de uma vogal frontal alta, mas, algumas vezes, de uma vogal central alta ou outra vogal. A vogal frontal mais baixa /é/ é derivada mais frequentemente de

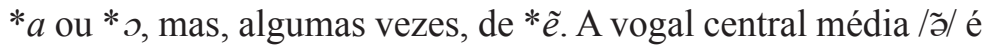
geralmente derivada de $* \tilde{a}$, enquanto a vogal central mais baixa $/ \tilde{a} /$ é derivada ou da correspondente vogal oral $* a$ ou de qualquer um dos vários fonemas vocálicos da Protolíngua. Finalmente, Ka / $\tilde{u} /$ é derivado de $* \tilde{u}$ ou de $* \tilde{o}$. (Davis 1966:20).

\section{Conclusão}

Resenhamos criticamente, como nos propusemos, os cinco trabalhos pioneiros acerca das relações entre Xokléng e Kaingáng, e entre essas línguas e a família Jê, com referência ao Proto-Jê. Apontamos, ao longo da análise, aqueles aspectos que, nos trabalhos em questão, mereceriam reanálise, seja por uma reorganização dos dados, seja por cotejamento com mais informação disponível do Kaingáng e do Xokléng atuais. Embora tenhamos buscado ser extensos, para efetivamente apresentar a argumentação e fundamentação sustentada por cada autor, a leitura dessas resenhas não dispensa a consulta à íntegra das obras originais.

Cremos que uma limitação recorrente nos estudos resenhados, com algum reflexo nas conclusões de cada um, é a adoção do modelo que conhecemos por "Fonêmica" norte-americana. Ao desconsiderar a noção de "sistema fonológico", contentando-se com elencar "inventários fonêmicos", ${ }^{54} \mathrm{o}$ modelo traz alguma dificuldade para refletir as mudanças fonológicas - de língua a língua, e de um estágio a outro de uma mesma língua - enquanto passagens de um sistema a outro sistema. Fazer avançar a investigação do Proto-Jê Meridional exige, segundo nossa perspectiva, esse tipo de abordagem para os estudos atuais e futuros. ${ }^{55} \mathrm{~A}$ observação crítica não invalida, no entanto, qualquer dos esforços representados naqueles trabalhos pioneiros, muito menos dispensa sua consulta e sua citação em qualquer estudo posterior a respeito do Proto-Jê (em especial, do Proto-Jê Meridional).

\footnotetext{
${ }^{54}$ Sobre essa dissenção central da Fonêmica seja em relação à Escola de Praga, seja em relação às ideias de Sapir, veja-se D’Angelis, 2004.

${ }^{55}$ Nosso relatório acadêmico de pós-doc avançou a investigação nessa direção, sobretudo em sua parte III.
} 


\section{Referências}

Câmara Jr., Joaquim Mattoso. 1959. Alguns radicais Jê. Rio de Janeiro: Museu Nacional.

D’Angelis, Wilmar R. 2004. O alinhamento pró-Estados Unidos da Fonologia no Brasil. Revista Brasileira de Linguística Aplicada 4:87-115.

D’Angelis, Wilmar R. 2008. Pensar o Proto-Jê Meridional e revisitar o Proto-Jê, numa abordagem pragueana. Relatório Acadêmico de Estágio Pós-Doutoral em Linguística Histórica. Universidade de Brasília.

Davis, Irvine .1966. Comparative Jê Phonology. Estudos Linguísticos. Revista Brasileira de Linguística Teórica e Aplicada 1(2):10-24.

Guérios, R. F. Mansur. 1945. O Xocrén é idioma Caingangue. Arquivos do Museu Paranaense IV:321-331.

Swadesh, Morris. Towards grater accuracy in lexicostatistics dating. IJAL (itálico) 21:121-137.

Wiesemann, Ursula (s.d.). Notas sobre Proto-Kaingáng: um estudo de quatro dialetos. Tradução de Miriam Lemle. Rio de Janeiro: Summer Institute of Linguistics. 21 páginas, m.s.

Wiesemann, Ursula. 1978. Os dialetos da língua Kaingáng e o Xokléng. Arquivos de Anatomia e Antropologia 3:197-217. Rio de Janeiro: Instituto de Antropologia Professor Souza Marques. 